\title{
ASSET INSULATORS
}

Gabriel Chodorow-Reich

Andra Ghent

Valentin Haddad

Working Paper 24973

http://www.nber.org/papers/w24973

\author{
NATIONAL BUREAU OF ECONOMIC RESEARCH \\ 1050 Massachusetts Avenue \\ Cambridge, MA 02138 \\ August 2018
}

We thank Bo Becker, Jonathan Berk, Markus Brunnermeier, Matthias Efing, Andrew Ellul, Zhiguo He, Ralph Koijen, Peter Kondor, Arvind Krishnamurthy, Craig Merrill, Onur Ozgur, Andrei Shleifer, David Sraer, Sascha Steffen, Jeremy Stein, and David Thesmar for helpful discussions, and participants at various conferences and seminars for their comments. Eben Lazarus and Tina Liu provided excellent research assistance. The views expressed herein are those of the authors and do not necessarily reflect the views of the National Bureau of Economic Research.

NBER working papers are circulated for discussion and comment purposes. They have not been peer-reviewed or been subject to the review by the NBER Board of Directors that accompanies official NBER publications.

(C) 2018 by Gabriel Chodorow-Reich, Andra Ghent, and Valentin Haddad. All rights reserved. Short sections of text, not to exceed two paragraphs, may be quoted without explicit permission provided that full credit, including $(\odot$ notice, is given to the source. 
Asset Insulators

Gabriel Chodorow-Reich, Andra Ghent, and Valentin Haddad

NBER Working Paper No. 24973

August 2018

JEL No. G01,G1,G14,G22,G32

\begin{abstract}
We propose that financial institutions can act as asset insulators, holding assets for the long run to protect their valuations from consequences of exposure to financial markets. We demonstrate the empirical relevance of this theory for the balance sheet behavior of a large class of intermediaries, life insurance companies. The pass-through from assets to equity is an especially informative metric for distinguishing the asset insulator theory from Modigliani-Miller or other standard models. We estimate the pass-through using security-level data on insurers' holdings matched to corporate bond returns. Uniquely consistent with the insulator view, outside of the 2008-2009 crisis insurers lose as little as 15 cents in response to a dollar drop in asset values, while during the crisis the pass-through rises to roughly 1 . The rise in pass-through highlights the fragility of insulation exactly when it is most valuable.

Gabriel Chodorow-Reich

Department of Economics

Harvard University

1805 Littauer Center

Cambridge, MA 02138

and NBER

chodorowreich@fas.harvard.edu

Andra Ghent

Department of Real Estate and

Urban Land Economics

Wisconsin School of Business

University of Wisconsin - Madison

Madison, WI

ghent@wisc.edu

\author{
Valentin Haddad \\ University of California, Los Angeles \\ Anderson School of Management \\ Office C4.19 \\ 110 Westwood Plaza \\ Los Angeles, CA 90024 \\ and NBER \\ vhaddad@ad.ucla.edu
}




\section{Introduction}

Financial intermediaries hold tens of trillions of dollars of securities. How does the value of these institutions respond to a decline in the prices of these securities? Under Modigliani-Miller, a dollar of assets translates directly into a dollar of firm value. In theories of financial distress, a decline in prices additionally reduces the financial health of the institution, yielding a more than one-to-one effect and potentially starting an adverse feedback loop in the financial system. An alternative view, held by many practitioners, is that certain types of financial institutions, such as banks, life insurers and pension funds, are long-term investors that can "ride out" fluctuations in asset prices without seeing their own valuations affected.

In this paper, we expound this second view and propose that some financial intermediaries act as asset insulators. We show that such a role emerges naturally in economies where trading frictions affect asset prices. Similar to arbitrageurs, insulators exploit different valuations of the same asset by different investors. More distinctively, an asset insulator creates value by buying and holding for the long run assets otherwise subject to valuation shocks in the open market. This activity results in the market value of an insulator's equity differing from the gap between the market value of its assets and liabilities. Our main empirical contribution is to build on this insight to present direct evidence of asset insulation in the form of the passthrough from asset holdings to equity, using a data set of 11.5 million corporate bond returns merged with security-level data on the asset positions and equity returns of publicly-traded life insurance companies.

We start our analysis with a model of an asset insulator in order to clarify the conditions under which they can exist and what shapes the evolution of their equity. Our theory highlights the interaction of two forces. First, the benefit from holding an asset

inside an insulator depends on the size of the wedge between the asset's market value and the value to a long-term investor. Second, a financial intermediary may have to liquidate its holdings on the open market if asset values deteriorate sufficiently. The risk of forced liquidation counteracts value creation from asset insulation. We derive an expression for the value of an insulator's equity and define the franchise value as the difference between the firm's equity and the market value of financial assets minus liabilities. The franchise value fluctuates in response to both changes in the value of the asset insulation function and the ability of intermediaries to perform it. The interaction of these forces generates predictions we can take to the data.

We do so in the context of life insurance companies, a sector which holds $\$ 4$ trillion 
of financial assets. The traditional view of life insurers emphasizes their expertise in pricing policy liabilities as their main source of value creation (Briys and De Varenne, 1997). Our theory instead emphasizes the asset side of insurers' balance sheets; liabilities matter insofar as they provide a stable source of funding to back asset insulation activities.

We use detailed, security-level regulatory data to confirm three main balance sheet predictions of the theory. First, insurers hold risky, illiquid assets. Their largest portfolio holdings are in corporate bonds, commercial mortgages, and non-Agency assetbacked securities; only about $10 \%$ of their holdings are in safe and liquid Treasury or Agency securities. Second, insurers execute trading strategies to target assets with market value below their long-run value. The typical security remains on an insurer's balance sheet for about 8 years, allowing insurers to generate value simply by purchasing illiquid assets and keeping those assets off of trading markets. Furthermore, insurers' secondary market purchases of corporate bonds concentrate in securities which have recently fallen in value but experience positive abnormal returns after purchase by an insurer. The positive post-purchase abnormal return survives controls for purchase date, rating, coupon, and maturity, suggesting that insurers actively seek bonds with market value below long-run value. Third, insurers have stable liabilities to back their asset holdings, primarily long-term life insurance contracts and annuities.

Our main empirical contribution is to combine the information in the share prices of publicly-traded insurers with data on their asset positions and market prices of those assets to compute the pass-through from a dollar of assets to equity. The relationship between these two market values provides a unique window into how insulation creates value. In normal times, the ability to insulate from transitory fluctuations in asset prices in the open market yields a pass-through into equity below 1 . As the risk of forced liquidation increases, however, the ability to insulate diminishes and even transitory fluctuations affect equity. Moreover, each lost dollar of assets pushes the firm closer to liquidation, reducing the value of insulation on the entire balance sheet. Thus, the pass-through rises during a crisis. This pattern is unique to the insulator theory; theories of financial institutions rooted in costs of financial distress or risk-shifting due to government guarantees do not predict this behavior.

A test of the pass-through must overcome the identification challenge that the observed return on asset holdings may be correlated with the change in value of other assets, of insurers' liabilities, and of the value of future business. We design an empirical strategy which exploits large, idiosyncratic movements in bond prices held by 
some insurers and not others. Specifically, we match daily cusip-level holdings of the assets on each publicly-traded insurer's balance sheet with the universe of corporate bond returns on each date. The combination of concentrated portfolio positions, leverage, and volatile bond returns generates insurer-level portfolio shocks with a standard deviation in excess of 25 basis points of market equity, large enough to make the test powerful. We obtain the pass-through by regressing the equity return on the portfolio shock in the cross-section of insurers.

Consistent with the predictions of the model, the pass-through differs in and out of the 2008-2009 financial crisis. Outside of the crisis, a dollar lost on assets creates an approximately 15 cent loss to equity value, economically and statistically significantly much less than one. The pass-through rises during the crisis. The data reject equality of the pass-through in and out of the crisis, but do not reject equality of the crisis passthrough and 1. We show extensive robustness to the definition of the portfolio shocks, control variables, and sample restrictions. Moreover, the pass-through rises more for those insurers most severely impacted by the crisis, providing further evidence of poor financial health during this period contributing to lower insulation from market movements.

Our final result demonstrates the importance of the insulator view to understanding the survival of the life insurance sector during the 2008-09 crisis. Specifically, without the value created by their asset insulation activities, the market equity of life insurers during the 2008-09 period would have declined by additional tens of billions of dollars, likely rendering much of the sector insolvent. This calculation involves two steps. First, the sharp drop in safe interest rates during 2008 increased the value of publicly-traded insurers' policy liabilities by an estimated $\$ 96$ billion. Second, the market value of the risky assets held by these insurers declined by $\$ 30$ billion. A constant franchise value would therefore have implied a more than $\$ 126$ billion loss in the value of insurers' equity. Instead, equity dropped by "only" $\$ 80$ billion. Through the lens of our theory, the $\$ 46$ billion increase in franchise value must reflect fire sale discounts and increases in illiquidity during the crisis which caused market prices to temporarily decline: insulation helped insurance companies withstand the brunt of the crisis. Nevertheless, the behavior of the pass-through during this period highlights a core tension in the provision of asset insulation, as the crisis coincided with a deterioration in the financial health of insurers, threatening their ability to insulate assets from market movements exactly when such insulation is most valuable.

The remainder of the paper proceeds as follows. We next situate our findings in the existing literature. We formalize the concept of an asset insulator in Section 2 
and derive the predictions for balance sheet behavior and the pass-through. Section 3 provides background on life insurers and describes our data. Section 4 presents aggregate balance sheet evidence for life insurers. Section 5 contains the pass-through exercise. In Section 6 we measure the change in franchise value during the financial crisis. Section 7 concludes.

Related literature. Our paper relates to a large body of work on financial institutions in episodes of economic trouble. Going back to Bernanke (1983), a large literature emphasizes how deteriorating health of financial institutions can amplify adverse conditions. He and Krishnamurthy (2013) and Brunnermeier and Sannikov (2014) articulate formal theories of this view motivated by the 2008-09 period. We focus instead on the ability of certain intermediaries to avoid frictions in the market for securities. In this insulator role, shocks originating on financial markets can actually be mitigated by the intermediary.

The life insurance industry during the 2008-09 crisis exemplifies both of these views. Consistent with an amplification role, Ellul, Jotikasthira, and Lundblad (2011) document that regulatory constraints prompted life insurers to liquidate some bond positions during this period, pushing the prices of these bonds further down, while Koijen and Yogo (2015) show how binding regulatory constraints distorted the pricing of insurance policies. Our work instead highlights how life insurers mitigated the link from security prices to the market equity of the financial sector. While insurers certainly suffered during the crisis, their ability to insulate prevented the destruction of nearly $\$ 50$ billion of market equity in the financial sector at a crucial moment.

An important ingredient for insulators to create value is the stability of their liabilities. Diamond and Dybvig (1983), Gorton and Pennacchi (1990), and Calomiris and Kahn (1991) discuss how financial institutions can manufacture stable liabilities. In the case of insurers, the long contractual horizon of policies naturally gives rise to stable liabilities. Our main focus is how such funding stability facilitates insulation in securities markets. Two papers related to ours illustrate such a comparative advantage in the context of commercial banks and closed-end funds. In Hanson, Shleifer, Stein, and Vishny (2015), commercial banks have "sleepy" liabilities because government deposit insurance makes depositors insensitive to the value of the bank's assets, allowing them to ride out periods of fire sales. In Cherkes, Sagi, and Stanton (2009), fully equity-financed closed-end funds face no redemption risk. Our framework emphasizes that any institution with stable liabilities may adopt the role of an asset insulator. 
Finally, an insulator is a specific type of arbitrageur. Hence, our work also relates to the literature on the limits to arbitrage. ${ }^{1}$ This literature has traditionally focused on sophisticated institutions created with the explicit goal of making profits by taking advantage of financial market inefficiencies. We highlight how a broader set of large financial institutions derive value from differences in valuation and how this activity shapes the evolution of the market equity of these institutions. Our approach echoes a literature which tries to resolve the closed-end fund puzzle by valuing the comparative advantage of the institution (Lee, Shleifer, and Thaler, 1991; Berk and Stanton, 2007; Cherkes et al., 2009). In addition, our results add to the evidence of multiple valuations of seemingly the same asset (e.g., Malkiel, 1977; Lamont and Thaler, 2003), in our case corporate bonds.

\section{What is an Asset Insulator?}

An insulator is an institution which protects assets from price fluctuations using a stable balance sheet. In this section, we formalize this definition and contrast it with three standard theories of financial institutions. We then discuss implications of asset insulation for balance sheet behavior. Finally, we construct the pass-through test to distinguish the insulator view from alternative theories.

\subsection{Model of Asset Insulator}

Our starting point is that two valuations for the same asset can coexist. One valuation is the price observed on the market where the asset is traded. This price reflects any transitory conditions in this market. The other valuation is a more stable long-term value, reflecting the value of the asset to a long-term investor. An asset insulator is an institution capable of exploiting such a valuation differential.

The existence of a valuation differential requires some limits to arbitrage. Otherwise, insulators would continue to expand their balance sheet until the difference between the market price and its value to an insulator disappeared. ${ }^{2}$ In Appendix A we present an equilibrium model of such a valuation differential and show how limits to arbitrage allow asset insulators to exist.

The objective of this paper is to study the behavior of insulators and to construct a test for their presence. The model that follows therefore takes as given the existence

\footnotetext{
${ }^{1}$ Shleifer and Vishny (1997) originate the term and provide the first formal model of it. Barberis and Thaler (2003) and Gromb and Vayanos (2010) provide surveys of the literature.

${ }^{2}$ We return to the specific nature of this constraint in Section 2.3.
} 
of a valuation differential and a limit to the size of the insulator. The model highlights the interaction of two forces. First, the benefit from holding the asset inside the insulator depends on the size of the wedge between market value and long-term value. Second, the risk of forced liquidation following poor performance counteracts value creation from asset insulation. We derive an expression for the value of an insulator's equity and use it to make testable predictions for balance sheet behavior. In addition, if an insulator itself is publicly traded, observing both the market value of its portfolio holdings and its equity provides a unique opportunity to jointly test for the presence of distinct valuations and the role of the institution as an insulator. We formalize this test as the pass-through.

Valuation inside and outside of the insulator. The institution can invest at date 0 in assets indexed by $j=1, \ldots, N$. The institution chooses a non-negative number of shares $s_{j}$ to invest in each asset. The assets have a continuous payout rate of $c$. The value of asset $j$ if held inside the insulator forever is $A_{j, t}^{\text {in }}$. This value follows a risk-neutral law of motion:

$$
\frac{d A_{j, t}^{\text {in }}}{A_{j, t}^{\text {in }}}=(r-c) d t+\sigma_{A, \text { agg }, j} d Z_{t}^{A}+\sigma_{A, \text { idio }, j} d Z_{j, t}^{A} .
$$

Asset value including payouts grows at the risk-free rate $r$ and has volatility exposure to an aggregate shock $\sigma_{A, \text { agg, } i}$ and an asset-specific shock $\sigma_{A, \text { idio }, i}$. The processes $\left\{Z_{t}^{A}\right\}$ and $\left\{Z_{j, t}^{A}\right\}$ are independent standard brownian motions.

The value of the assets when traded on the open market differs from the value inside the insulator by a factor $\omega_{j, t}$ :

$$
A_{j, t}^{\text {out }}=\omega_{j, t} A_{j, t}^{\text {in }}
$$

where the wedge $\omega_{j, t}$ follows a mean-reverting process:

$$
d \omega_{j, t}=-\kappa_{\omega, j}\left(\omega_{j, t}-\bar{\omega}_{j}\right) d t+\sigma_{\omega, \text { agg }, j} \sqrt{\omega_{j, t}} d Z_{t}^{\omega}+\sigma_{\omega, \text { idio }, j} \sqrt{\omega_{j, t}} d Z_{j, t}^{\omega}
$$

The parameters $0<\bar{\omega}_{j}<1, \sigma_{\omega, \text { agg, }, j}$, and $\sigma_{\omega, \text { idio }, j}$ control the mean and volatility of $\omega_{j, t}$, and $\kappa_{\omega, j}$ is the speed of reversion to the mean. ${ }^{3}$ For clarity of exposition, we assume for now that the shocks to the wedge are orthogonal to the shocks to the inside value.

\footnotetext{
${ }^{3}$ We assume that $2 \kappa_{\omega} \bar{\omega}>\left(\sigma_{\omega, \text { agg }, j}^{2}+\sigma_{\omega, \text { agg }, j}^{2}\right)$ to ensure that $\omega$ is always strictly positive.
} 
We define the outside value of the portfolio as $A_{t}^{\text {out }}=\sum_{j} s_{j} \omega_{j, t} A_{j, t}^{\text {in }}$, the inside value as $A_{t}^{\text {in }}=\sum_{j} s_{j} A_{j, t}^{\text {in }}$, and the portfolio wedge as $\omega_{t}=A_{t}^{\text {out }} / A_{t}^{\text {in }}$.

The processes $\omega_{j, t}$ determine the wedges between asset values inside and outside the firm. Under the asset insulator view, assets typically have more value inside than outside the firm, $\omega_{j, t}<1$. A lower value of $\omega_{j, t}$ corresponds to a more depressed market price and therefore a larger gain from holding the asset inside the firm. The existence of a time-varying wedge $\omega_{j, t}$ and the property $\bar{\omega}_{j}<1$ arise naturally in general equilibrium models with limits to arbitrage. ${ }^{4}$

Firm financing structure and liquidation. The assets of the firm finance payments to three sets of agents: debt holders, asset managers, and shareholders. The debt takes the form of a perpetual console bond, with payments $\ell$ due continuously. Asset managers receive payments proportional to the amount of assets they manage, a flow $k A_{t}^{\text {in }}$ each period. These payments have a broader interpretation than the direct compensation of asset managers and represent any proportional costs linked with the management of the assets. Shareholders are the residual claimants.

We assume a rigid capital structure to capture the possibility of financial distress and forced liquidation of the firm's assets. We model such forced liquidation by a threshold condition $\mathcal{H}\left(A_{t}^{\text {out }}, A_{t}^{i n}\right) \leq 0$ at which liquidation occurs, where the function $\mathcal{H}$ is increasing in both arguments and captures the financial health of the firm. For example if $\mathcal{H}\left(A^{\text {out }}, A^{\text {in }}\right)=A^{\text {out }}-\underline{A}$, liquidation occurs when the market value of the portfolio reaches a threshold $\underline{A}$. Let $T$ denote the liquidation stopping time, i.e., $T=$ $\arg \min _{t} \mathcal{H}\left(A_{t}^{\text {out }}, A_{t}^{\text {in }}\right)=0$. The proceeds $A_{T}^{\text {out }}$ from liquidating the portfolio first pay debt holders in full, with equity claimants receiving the remaining value. ${ }^{5}$

While stylized, the single threshold condition captures in a parsimonious way the increased prospect of liquidation into the open market when an insurer faces financial distress. In practice, intermediaries face a combination of capital requirements, accounting rules, and direct regulatory pressure which make liquidation of the portfolio

\footnotetext{
${ }^{4}$ See Appendix A for one such model featuring limits to arbitrage and noise trader risk. In that model, noise trader demand causes time variation in $\omega_{t}$. Rational investors then require $\bar{\omega}<1$ to compensate for their bearing noise-trader risk. Other motivations include temporary fire sale discounts (Shleifer and Vishny, 2011), the price impact from large trades, transaction costs that distort prices (Amihud and Mendelson, 1986; Duffie, Gârleanu, and Pedersen, 2005), or differences in information (Berk and Stanton, 2007).

${ }^{5}$ With a threshold based on outside value only, debt holders always get fully repaid as long as $\underline{A} \geq \ell / r$. Because $\omega_{t}$ is not bounded below, no threshold can ensure full payment to debt holders if the boundary depends on the inside value of assets. In this case, we assume $\mathcal{H}\left(A_{t}^{\text {out }}, A_{t}^{\text {in }}\right)$ is sufficiently conservative that almost always $\omega_{T} A_{T}^{i n}>\ell / r$ and neglect the potential losses for debt holders in our calculations. In the case of insurers, recovery rates in insolvencies have typically exceeded $75 \%$. We come back to the possibility of risky debt in our empirical analysis.
} 
a progressive rather than a discrete event. In the case of insurers, Ellul et al. (2011) provide evidence of capital-constrained insurers selling downgraded corporate bonds, Ellul, Jotikasthira, Lundblad, and Wang (2015) show how the interaction of accounting rules and asset downgrades led to early selling of assets, and Merrill, Nadauld, Stulz, and Sherlund (2014) document liquidations of mortgage-backed securities by capital-constrained insurers in distressed markets.

Equity. The firm chooses portfolio shares $\left\{s_{j}\right\}$ to maximize the value of its equity at date 0 , where the valuation equation for equity is

$$
E_{t}=\mathbb{E}_{t}\left[\int_{t}^{T} e^{-r(\tau-t)}(c-k) A_{\tau}^{\text {in }} d \tau+e^{-r(T-t)} \omega_{T} A_{T}^{i n}-\int_{t}^{\infty} e^{-r(\tau-t)} \ell d \tau\right] .
$$

The first integral gives the asset payouts net of management fees before liquidation. The second term is the liquidation value of the assets. The last term is the cost of policy liabilities.

To understand the interaction of insulation and financial health, it helps to consider the two polar cases of $\mathcal{H}\left(A_{t}^{\text {in }}, A_{t}^{\text {out }}\right) \gg 0$ (far from liquidation) and $\mathcal{H}\left(A_{t}^{\text {in }}, A_{t}^{\text {out }}\right) \rightarrow 0$ (at liquidation):

$$
\begin{aligned}
\text { Far from liquidation: } & E_{t}\left(A_{t}^{\text {in }}, \omega_{t}\right) \approx A_{t}^{\text {in }} \frac{c-k}{c}-\frac{\ell}{r}, \\
\text { At liquidation: } & E_{t}\left(A_{t}^{\text {in }}, \omega_{t}\right)=\omega_{t} A_{t}^{\text {in }}-\frac{\ell}{r} .
\end{aligned}
$$

The first term of equation (5) is the net-of-management-fees present value of assets inside the firm without default. The second term subtracts the present value of policy liabilities. Notably, far from liquidation the value of equity does not depend on the wedge $\omega_{t}$, as the firm uses its advantage as a long-hold investor to fully insulate equity holders from market fluctuations in the value of the portfolio which do not reflect future payouts. Conversely, at the liquidation boundary the value of equity simply equals the liquidation value of the assets on the open market less the value of liabilities. The insurer loses its ability to collect the inside value of the assets because they will go back to the market at liquidation.

In the intermediate region the value of the insurer moves smoothly between these two extremes. In Appendix B.1 we derive a closed-form expression for the value of equity as a function of the state variables $A_{t}^{\text {in }}$ and $\omega_{t}$ for the special case of one risky asset and where the liquidation boundary depends on the inside value only, 
$\mathcal{H}\left(A^{\text {out }}, A^{\text {in }}\right)=A^{\text {in }}-\underline{A}:$

$$
E_{t}=A_{t}^{\text {in }} \frac{c-k}{c}-\frac{\ell}{r}+\left(\frac{A_{t}^{\text {in }}}{\underline{A}}\right)^{-f(r)} \underline{A}\left(\bar{\omega}-\frac{c-k}{c}\right)+\left(\frac{A_{t}^{\text {in }}}{\underline{A}}\right)^{-f\left(r+\kappa_{\omega}\right)} \underline{A}\left(\omega_{t}-\bar{\omega}\right),
$$

with $f(\alpha)=\frac{r-c-\frac{1}{2} \sigma_{A}^{2}+\sqrt{\left(r-c-\frac{1}{2} \sigma_{A}^{2}\right)^{2}+2 \sigma_{A}^{2} \alpha}}{\sigma_{A}^{2}}$. Equation (7) contains two new terms relative to equation (5). The third term of equation (7) is the average change in value in liquidation if $\omega_{t}=\bar{\omega}, \underline{A}\left(\bar{\omega}-\frac{c-k}{c}\right)$, discounted by the time to liquidation, $\left(\frac{A_{t}^{\text {in }}}{\underline{A}}\right)^{-f(r)}=$ $\mathbb{E}_{t}\left[e^{-r(T-t)}\right]$. The fourth term adjusts the discounted change in value in liquidation for transitory deviations in the liquidation value of the assets.

Franchise value. We define the firm's franchise value as the value of the equity less the firm value under Modigliani-Miller. The Modigliani-Miller valuation, $E_{t}^{\mathrm{MM}}$, is given by the market value of the assets minus that of liabilities:

$$
E_{t}^{\mathrm{MM}}=\omega_{t} A_{t}^{\mathrm{in}}-\frac{\ell}{r}
$$

The theory incorporates three determinants of franchise value $E_{t}-E_{t}^{\mathrm{MM}}$. Most important, when $\omega_{t}<1$ the value of assets inside the firm exceeds the value outside the firm, i.e. $A_{t}^{\text {in }}>A_{t}^{\text {out }}$. This ability of the intermediary to protect asset valuation from the wedge $\omega_{t}$ provides the main source of value creation. The other two forces mitigate this ability to create value. First, in bad states of the world, the firm must liquidate its assets, collecting only the market value. This effect prevents the structure from obtaining the full difference $\left(1-\omega_{t}\right) A_{t}^{\text {in }}$. Second, not all the benefits from keeping assets inside the insulator accrue to shareholders. The proportional cost $k$ captures the value paid to other stakeholders of the firm - asset managers and other employees - and the proportional operational costs of running the balance sheet. Depending on whether or not the present value of those costs exceeds the difference between asset valuations inside and outside the firm, the firm will trade at a premium or discount relative to net asset value. In the special case of no default, the firm trades at a premium if and only if $\omega_{t}<(c-k) / c$.

\subsection{Other Theories}

Our framework nests three other theories of financial institutions which we will contrast with the insulator view: irrelevance, costly financial distress, and liability guarantees. These theories do not involve different valuations of the asset so we set $\omega_{t}=1$ 
and $k=0$.

Irrelevance. The simplest view of financial institutions is that they are irrelevant. Under the Modigliani-Miller theorem, a financial institution acts as a shell, raising capital at market prices and buying securities at market prices. The firm itself creates no value, i.e., franchise value is zero, and portfolio allocation is indeterminate.

Costs of financial distress. A small cost of bankruptcy, or more generally of financial distress, breaks this indeterminacy. This cost could involve the inefficient liquidation of non-financial assets, loss of expertise or market power in pricing life insurance policies, or the destruction of reputation capital. We materialize such a cost by a fixed payment $D$ made at liquidation. The valuation equation becomes:

$$
E_{t}=\mathbb{E}_{t}\left[\int_{t}^{T} e^{-r(\tau-t)}(c-k) A_{\tau} d \tau+e^{-r(T-t)}\left(A_{T}-D\right)-\int_{t}^{\infty} e^{-r(\tau-t)} \ell d \tau\right]
$$

Liability guarantees. Financial institutions may derive some private value from government guarantees of their liabilties. These guarantees may include explicit backing of liabilities, for example deposit insurance in the case of commercial banks and state guaranty funds in the case of life insurers, as well as an implicit expectation of bailouts following large shocks. The presence of guarantees allows intermediaries to extract private value by investing in risky assets. A negative value of the fixed payment $D$ in equation (9) captures such guarantees or bailouts. ${ }^{6}$

\subsection{Balance Sheet Implications}

We now present implications of the theory for the balance sheet behavior of life insurance companies.

Insulators hold risky and illiquid assets. A first question is whether insulators deliberately invest in risky assets. In the case of irrelevance, the portfolio position is indeterminate. This is the world of Modigliani-Miller: the firm cannot change its value through changing positions in publicly traded securities. A small positive cost of financial distress, $D>0$, breaks this indeterminacy. In this case, it is always

\footnotetext{
${ }^{6}$ Even if the guarantees accrue to debtholders, their presence will affect the value of equity. For instance, the insurance company might let liabilities go under water before liquidating to get bailed out. If a fraction $\Delta$ of liabilities is insured, $D=\Delta \ell / r$, this would correspond to a liquidation threshold $\mathcal{H}\left(A^{\text {in }}, A^{\text {out }}\right)=A^{\text {out }}-(1-\Delta) \ell / r$.
} 
optimal for the firm to keep enough risk-free assets to never default. For insurers, this strategy requires holding riskless assets with the same duration as their liabilities, a strategy known as liability-matching.

However, with a non-zero wedge, the firm can create franchise value by holding risky illiquid financial assets. In this situation, it is always valuable to expose the firm to some default risk. Formally, assume the insulator can access two assets, a risky asset with $\omega_{0}=\bar{\omega}<1$ and a risk-free asset with $\bar{\omega}=1$ and $\sigma_{\omega}=0$. In this case, we prove in Appendix $\mathrm{C}$ that the optimal portfolio position in the risky asset is always large enough that the liquidation probability is strictly positive. Intuitively, the risk of liquidation from investing more in the risky asset has a negligible effect on the present value of existing insulation profits relative to the first-order gain of new insulation profits.

The guarantee view, $D<0$, also predicts risk-taking by insurance companies because of risk-shifting incentives. However, the guarantee view does not make predictions about what types of risks insurers will take.

Insulators purchase assets with low $\omega$. Rather obviously, insulators should purchase assets with market prices below their long-run value, $\omega_{j, t}<1$. Among these, the optimal portfolio puts more weight on assets trading at deeper discounts. Two complementary portfolio strategies can achieve this goal, with different information requirements and different empirical signatures. First, an asset manager can target specific assets which have temporarily dropped in value, that is $\omega_{j, t}<\bar{\omega}_{j}$. Such assets will have experienced poor past performance as $\omega_{j, t}$ dropped. Importantly, they will also exhibit high future returns as $\omega_{j, t}$ tends to revert back to its mean. This excess performance gets capitalized as franchise value from insulation. Pursuing this strategy requires asset management capable of attributing a low market price to a temporarily low value of $\omega_{j, t}$ rather than a low long-term value $A_{j, t}^{\text {in }}$.

Alternatively, the manager might focus on assets with a more permanent notion of illiquidity: low values of $\bar{\omega}_{j}$. This strategy requires less managerial expertise because the manager need know only the invariant parameter values for the asset and not the current realization of $\omega_{j, t}$. More simply, the manager might select asset classes for which the average $\omega_{j, t}$ is low without needing to identify $\bar{\omega}_{j}$ for any specific asset. These assets exhibit high future returns as the liquidity premium gets realized, but do not necessarily have a past drop in market value.

Going from coarser to more complex information sets entails managerial costs, which we summarize with the constant $k$. The actual portfolio strategy followed 
thus trades off the insulation benefits from selecting low $\omega_{j, t}$ assets with the costs of identifying these assets, similar to active mutual funds. ${ }^{7}$ In addition, different asset managers might specialize in identifying different types of low $\omega_{j, t}$ assets. As in Van Nieuwerburgh and Veldkamp (2010) and Kacperczyk, Van Nieuwerburgh, and Veldkamp (2016), it is therefore natural to expect insulators to invest in heterogenous and possibly undiversified portfolios of assets.

Insulators have stable liabilities. A crucial element behind the value of an insulator is the ability to hold assets for the long-run to capture their inside value. Institutions engaging in such activities benefit from stable sources of funds. In our baseline model, debt is a perpetuity so that liquidation only occurs following poor asset performance. However, we can explore the role of rollover risk by including another, exogenous, source of liquidation, arriving each instant with probability $\lambda d t{ }^{8}$ When insulation is valuable, we obtain immediately that the franchise value is decreasing in $\lambda$; rollover risk reduces insulation (see appendix $\mathrm{C}$ for details).

This result points to the frictions in financing markets which limit the capital flowing to insulators. Obtaining long-term financing such as equity and large amounts of long-term debt can be challenging, in particular for financial institutions. Such frictions can explain the preponderance of open-end contracts for mutual funds or the frequent use of short-term debt in the shadow banking sector. Meanwhile, insurance companies naturally have access to a captive source of funding - policy liabilities explaining why they can host insulation activities. Even so, the optimal size of insurers should equate the marginal cost of funds to the benefit from providing additional insulation. If insurers face an upward-sloping cost of stable funding, for example because of a downward-sloping demand curve for insurance policies, then they naturally will not grow large enough to compete away all insulation profits.

\subsection{The Pass-Through}

While it offers a source of value creation distinct from that of alternative theories, the insulator view is not uniquely characterized by its balance sheet implications. A unique opportunity to discriminate among these theories arises when the institution

\footnotetext{
${ }^{7} \mathrm{~A}$ key difference to standard open-end funds is that the capital is committed for the long-run rather than for each period. So while asset managers may capture some of the ex ante surplus to insulation, variation in these benefits will not be offset by changing management costs. Berk and Stanton (2007) discuss at length this contrast with the model of Berk and Green (2004).

${ }^{8}$ For example, one way to capture debt of maturity $m$ with a probability $p$ of not rolling over is by setting $\lambda=p / m$.
} 
is publicly traded. In this case, both the market value of the assets and the market value of the institution's equity may be observable. We now turn to a particular empirical moment of the data exploiting this feature to test for insulation: the passthrough from assets to equity.

We formally define the pass-through $P T$ as the change in the value of firm equity when the value of the asset on the open market changes by $\$ 1$. This object corresponds to the coefficient of a regression of changes in firm value on changes in the outside value of the asset:

$$
P T=\frac{\operatorname{cov}\left(d E_{t}, d A_{t}^{\text {out }}\right)}{\operatorname{var}\left(d A_{t}^{\text {out }}\right)}
$$

Three features of the pass-through make it attractive for distinguishing the insulator theory. First, it is a measurable relationship between two observable market outcomes; it does not require the econometrician to separately identify shocks due to $\omega$, a challenging proposition. Second, the pass-through nonetheless depends on the relationship between firm value and the wedge $\omega$. Because variation in the outside value of the assets, $d A_{t}^{\text {out }}$, comes from changes in the inside value, $d A_{t}^{\text {in }}$, and changes in the wedge, $d \omega_{t}$, the pass-through aggregates the response to the two types of shocks, weighted by their variances. Third, changes in the pass-through in a crisis illuminate how the institution's financial health affects its ability to insulate.

We next generate predictions for the pass-through for extreme cases of financial health and show how they distinguish the insulator theory as long as $V_{\omega}>0$, where $V_{A}$ and $V_{\omega}$ denote the variance weights. To obtain closed form solutions, we simplify to the case of a single asset and liquidation boundary based on inside value. ${ }^{9}$ Appendix B.3 shows using numeric simulations that these predictions are robust to making the liquidation threshold a function of the outside value and allowing for correlated shocks to the inside value and to the wedge.

\footnotetext{
${ }^{9}$ Using Ito's lemma on the expression for $E_{t}$, we derive the pass-through (see Appendix B.2):

$$
\begin{aligned}
P T= & V_{A}\left[\frac{\frac{c-k}{c}}{\omega_{t}}-\frac{f\left(r+\kappa_{\omega}\right)}{\omega_{t} A_{t}^{\text {in }}}\left(\frac{A_{t}^{\text {in }}}{\underline{A}}\right)^{-f\left(r+\kappa_{\omega}\right)} \underline{A}\left(\omega_{t}-\bar{\omega}\right)-\frac{f(r)}{\omega_{t} A_{t}^{\text {in }}}\left(\frac{A_{t}^{\text {in }}}{\underline{A}}\right)^{-f(r)} \underline{A}\left(\bar{\omega}-\frac{c-k}{c}\right)\right] \\
& +V_{\omega}\left[\left(\frac{A_{t}^{\text {in }}}{\underline{A}}\right)^{-f\left(r+\kappa_{\omega}\right)-1}\right] .
\end{aligned}
$$
}


Far from liquidation. Consider first the case when the firm is in good financial health, far from liquidation. We have approximately:

$$
P T_{\text {safe }}=\left.P T\right|_{\mathcal{H}\left(A_{t}^{\text {in }}, A_{t}^{\text {out }}\right) \gg 0} \approx V_{A} \frac{\frac{c-k}{c}}{\omega_{t}}
$$

First, when the firm is in good financial health, it can completely fulfill its role of insulating the assets from the market. Therefore, shocks to the wedge $\omega_{t}$ do not impact firm value at all. This isolation reduces the pass-through. In the limiting case where $d \omega_{t}$ shocks account for all variation in market values, the pass-through converges to 0 .

Second, the impact of shocks to inside value $d A_{t}^{\text {in }}$ on the firm relative to the outside value depends on whether the firm trades at a premium or at a discount, defined by the term $\frac{c-k}{c} / \omega_{t}$ which multiplies the variance share. Higher values of $\omega_{t}$ due to, for example, more liquid markets, reduce the premium, lowering the impact of valuation shocks on the firm value relative to market value.

Putting these two forces together, the asset insulator view can rationalize a low pass-through during episodes when insurers are in good financial health and markets are liquid.

At liquidation. Consider now the other extreme case when the firm is converging to liquidation. In that case, we have:

$$
P T_{\text {liquidation }}=\left.P T\right|_{\mathcal{H}\left(A_{t}^{\text {in }}, A_{t}^{\text {out }}\right) \rightarrow 0}=P T_{\text {safe }}+V_{\omega}+V_{A}\left[\frac{f\left(r+\kappa_{\omega}\right)}{\omega_{t} A_{t}^{\text {in }}}\left(\bar{\omega}-\omega_{t}\right)+\frac{f(r)}{\omega_{t} A_{t}^{\text {in }}}\left(\frac{c-k}{c}-\bar{\omega}\right)\right] .
$$

When the intermediary gets close to liquidation, two main differences arise. First, notice the term $V_{\omega}$. With liquidation imminent, changes in the market value of the assets affect the value of the firm directly because they determine how much is collected at liquidation. Hence shocks to the wedge $d \omega_{t}$ now transmit one-to-one to firm value.

Second, as the financial health of the firm deteriorates, the value of all assets converge to their outside value. In particular, during episodes of low $\omega_{t}$ this force further decreases firm value; the term in brackets is negative. This is an endogenous cost of financial distress: poor asset performance, by bringing the firm closer to liquidation, lowers the franchise value from insulation. In illiquid times, the pass-through is therefore larger. 
In contrast to good conditions, the combination of low financial health and illiquidity pushes the pass-through to higher values, potentially larger than 1 . This behavior illustrates the tension arising in periods of low asset valuation: while franchise value increases because of a low $\omega_{t}$, the losses due to a potential liquidation also increase, generating a higher pass-through.

Empirical predictions. Putting these considerations together, we can summarize predictions for the behavior of the pass-through around the financial crisis of 20082009. To map various periods to the model, we consider insurers to be in good financial health $\left(\mathcal{H}\left(A_{t}^{\text {in }}, A_{t}^{\text {out }}\right) \gg 0\right)$ and assume a small wedge between the inside and outside value of assets ( $\omega_{t}$ close to 1$)$ before and after the crisis. In contrast, the crisis is a period of low financial wealth $\left(\mathcal{H}\left(A_{t}^{\text {in }}, A_{t}^{\text {out }}\right) \rightarrow 0\right)$ and a larger wedge (low $\left.\omega_{t}\right)$. We can thus compare the pass-through in and out of the crisis.

Prediction 1. The pass-through out of the crisis is less than 1, reflecting institutions' ability to insulate assets from the market.

Prediction 2. The pass-through increases during the crisis. The pass-through during the crisis can be larger than 1, reflecting the deterioration in the ability to insulate assets from the market.

Figure 1 illustrates these predictions graphically. The figure plots equity valuations as a function of the outside value of the asset $A^{\text {out }}$. The figure contains three lines: the Modigliani-Miller benchmark (dashed green line), the equity for a fixed, high $\omega$ (the solid blue line), and the equity for a fixed, low $\omega$ (the dotted red line). The Modigliani-Miller benchmark has a slope of 1 . The point $\mathrm{N}$ (for normal) corresponds to out of the crisis, with a high $\omega$ and high $A^{\text {in }}$. The point $\mathrm{C}$ (for crisis) corresponds to insurers during the crisis, with a low $\omega$ and low $A^{\text {in }}$. The slopes of the blue and red lines give the conditional pass-through with respect to a change in the outside asset value coming from a change in $A^{\text {in }}$, while the dashed black lines give the conditional pass-through with respect to a change in the outside asset value coming from a change in $\omega$ at the two points $\mathrm{N}$ and $\mathrm{C}$. Both conditional pass-throughs rise at point $\mathrm{C}$ relative to point $\mathrm{N}$, generating a higher unconditional pass-through at point $\mathrm{C}$ as well.

Pass-through to idiosyncratic shocks. Our empirical implementation in section 5 measures the pass-through in response to an idiosyncratic shock to the market 
Figure 1: Pass-through in the Asset Insulator Framework

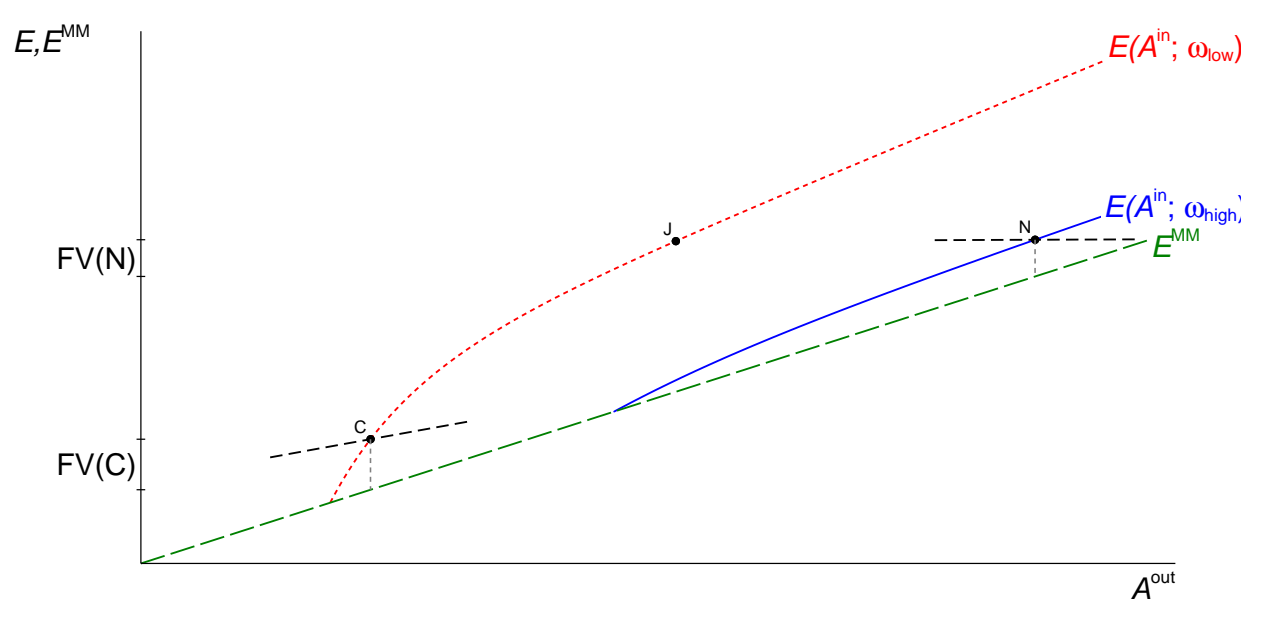

Notes: The figure illustrates the relationship between equity and asset value in the asset insulator framework. The dashed green line is the Modigliani-Miller benchmark and has a slope of 1 . The solid blue line plots equity as a function of the outside asset value for a fixed value $\omega_{\text {high }}$, while the dotted red line plots equity as a function of the outside asset value for a fixed value $\omega_{\text {low }}$. The slopes of the blue and red lines give the conditional pass-through with respect to a change in the outside asset value coming from a change in $A^{\text {in }}$. The slopes of the dashed black lines give the conditional pass-through with respect to a change in the outside asset value coming from a change in $\omega$ at the two points $\mathrm{N}$ (for normal) and $\mathrm{C}$ (for crisis). Point $\mathrm{J}$ shows the equity value holding $A^{\text {in }}$ fixed at its value at point $\mathrm{N}$ but for $\omega_{\text {low. }}$. The distance between the equity value and the Modigliani-Miller benchmark gives the franchise value (FV) and is shown on the vertical axis for the two points $\mathrm{N}$ and $\mathrm{C}$.

price of asset $i$. To relate this measure to the discussion so far, focus on the risky terms of the equity evolution to write:

$$
d E_{t}=\ldots d t+\sum_{j} \frac{\partial E}{\partial A_{j}} d A_{j, t}+\sum_{j} \frac{\partial E}{\partial \omega_{j}} d \omega_{j, t} .
$$

The overall pass-through is a weighted average of these partial derivatives, where the weights correspond to the variance contribution of the various shocks to the total outside asset value. The pass-through to idiosyncratic shocks is a weighted average of the same partial derivatives, but putting weight only on idiosyncratic shocks to asset $i$. In other words, the pass-through to idiosyncratic shocks reflects the same economic forces as described above and the same predictions in and out of the crisis period hold. However, the variance shares $V_{A}$ and $V_{\omega}$ might differ. The idiosyncratic pass-through therefore constitutes a valid test of the theory even if the magnitude differs from the pass-through to aggregate shocks. 
Table 1: Pass-Through Behavior under Alternative Theories

\begin{tabular}{l|cc} 
& Out of crisis & During crisis \\
\hline Irrelevance & 1 & $=$ \\
\hline Insulator & $<1$ & $\uparrow$ \\
\hline Costs of Financial Distress & $>1$ & $\uparrow$ \\
\hline Guarantees & $<1$ & $\downarrow$
\end{tabular}

Uniqueness of the pass-through predictions. Under the irrelevance view, the value of the firm is exactly equal to the market value of its asset, and therefore $P T^{\mathrm{MM}}=1$ always. Any deviation from 1 in the pass-through must come from changes in franchise value in response to changes in asset values. Costs of financial distress can only generate a pass-through above one, as losing a dollar of assets pushes the insurer closer to default and lowers franchise value. Policy guarantees can generate a pass-through less than one, since the value of the guarantee rises as the insurer moves closer to default. However, this effect is stronger in periods of high financial distress, implying a smaller pass-through during the crisis and for more distressed insurers. Formally, all these results comes from the cost $D$, which acts as a short (or long when $D<0$ ) position in an out-of-the-money put option. ${ }^{10}$ This position has a positive Delta which increases as the option gets closer to being at-the-money and therefore gets added to the baseline pass-through of 1 .

Table 1 summarizes these predictions and highlights how measuring the passthrough in and out of the crisis provides a unique test of the insulator theory against these alternatives.

\section{Background on Life Insurers and Data}

In the remainder of the paper we confront the predictions of the insulator theory with data, using the life insurance sector as our empirical laboratory. This sector is large, managing assets in excess of $20 \%$ of GDP, and we make use of detailed regulatory data on their asset holdings. We provide here a brief background on the life insurance

\footnotetext{
${ }^{10}$ More precisely, this is a digital put option which pays $D$ when hitting the liquidation threshold from above.
} 
Table 2: Assets Under Management at Life Insurers

\begin{tabular}{lccc}
\hline \hline & FAUS & SNL & Traded \\
\hline & & (Percent of GDP) & \\
2006 & 21.2 & 21.3 & 5.6 \\
2010 & 21.9 & 22.0 & 5.8 \\
2014 & 21.6 & 21.8 & 5.2 \\
\hline \hline
\end{tabular}

Notes: The table shows total general account assets under management at life insurance companies as reported in the Financial Accounts of the United States table L.116.g (FAUS), for all life insurance companies in the SNL database (SNL), and for the 15 life insurers in our publicly-traded sample (Traded).

sector and our data.

Like all financial institutions, insurers issue liabilities and invest in assets. The type of liabilities issued, primarily life insurance contracts and annuities, defines what it means to be a life insurer for regulatory purposes. Insurers segregate their balance sheets into general account assets which back fixed rate liabilities and death benefits, and separate account assets linked to variable rate products. As their name suggests, gains and losses on separate account assets flow directly to the policyholder and hence do not directly affect the equity in the insurance company. We exclude separate accounts in all of our analysis hereafter. Insurers issue two broad types of liabilities against their general account assets: fixed rate (either annuities or life insurance contracts), and variable rate with minimum income guarantees. ${ }^{11}$

State guaranty funds protect policyholders against the risk of insurer default up to a coverage cap. In exchange, insurers are subjected to regulation at the state level. Since the 1990s, such regulation has taken the form of a risk-based capital regime.

Our data on asset holdings come from mandatory statutory annual filings by insurance companies in operation in the United States to the National Association of Insurance Commissioners (NAIC). We use the version of these data provided by SNL Financial. Our main sample includes all life insurers in the United States and covers the period 2004-2014. In sections 5 and 6, we consider a subsample of publicly-traded U.S. life insurers that are substantively life insurers. ${ }^{12}$ Table 2 reports the total quan-

\footnotetext{
${ }^{11}$ See Paulson, Rosen, McMenamin, and Mohey-Deen (2012) and McMillan (2013) for an overview of the different products life insurers offer consumers. Koijen, Van Nieuwerburgh, and Yogo (2016) discuss the demand for the various products. Koijen and Yogo (2016) describe additional complications relating to how liabilities appear on the balance sheet or are ceded to reinsurance subsidiaries.

${ }^{12}$ The set of publicly-traded insurers (tickers) in our sample is: Aflac Inc. (AFL), Allstate Corp. (ALL), American Equity Investment (AEL), American National Insurance (ANAT), Citizens Inc. (CIA), CNO Financial Group Inc. (CNO), Farm Bureau Financial Services (FFG), Independence Holding
} 
tity of general account assets under management in the life insurance industry as a fraction of GDP. The first column uses data from the Financial Accounts of the United States (FAUS, formerly known as the Flow of Funds). General account assets exceed $20 \%$ of GDP. For comparison, in 2014 assets of commercial banks equaled $77 \%$ of GDP, assets of property and casualty insurers 9\% of GDP, and assets of closed-end funds $2 \%$ of GDP. The second column reports general account assets for the universe of insurers in the SNL database. The FAUS and SNL track each other extremely closely; in fact, SNL provides the source data for the FAUS. The third column reports assets at the life insurers in our publicly-traded subsample. This subset of insurers manages roughly one quarter of total insurer assets despite containing only 15 of the approximately 400 insurance companies in the SNL data.

\section{Balance Sheet Evidence}

Our model of asset insulators made the following predictions for insurers' balance sheets: they should hold risky, illiquid assets; they should target their purchases toward assets with low $\omega$; and they should have stable liabilities. We now verify these predictions.

\subsection{Insurers Hold Risky and Illiquid Assets}

Table 3 summarizes the holdings of life insurance companies. The left panel shows the portfolio shares of different asset categories. Insurers hold relatively few riskless, liquid U.S. Government securities, with Treasuries constituting less than $4 \%$ of insurers' assets and holdings of Agency bonds and MBS falling from approximately $10 \%$ of assets in 2006 to less than $6 \%$ in 2014. Instead, bonds of non-financial corporations constitute the largest single category at roughly $30 \%$ of assets. Insurers also hold commercial mortgages and non-agency structured finance securities in larger

(IHC), Kansas City Life Insurance Co. (KCLI), Lincoln Financial Group (LNC), MetLife Inc. (MET), Phoenix Companies Inc. (PNX), Prudential Financial Inc. (PRU), Protective Life (PL), and Torchmark Corp. (TMK). Our publicly-traded sample excludes financial conglomerates or foreign insurers that have a small fraction of their assets in U.S. life insurance companies, and reinsurers. Many insurance companies have multiple subsidiaries. To maximize the comprehensiveness of our data, we include holdings of Property and Causalty (P\&C) subsidiaries as well. SNL aggregates the data up to the parent company level and applies inter-company adjustments to present historical balance sheet data on an "As-is" data. We convert to an "As-was" basis by subtracting balance sheet holdings for companies acquired after the filing date. Similarly, for major mergers and acquisitions, we add in holdings of insurance companies that were divested by the parent company after the reporting date but before 2014. 
Table 3: Life Insurer Asset Allocation

\begin{tabular}{lrrrrrrr}
\hline \hline & \multicolumn{3}{c}{ Portfolio share: } & \multicolumn{3}{c}{ 2006 category share by rating: } \\
\cline { 2 - 3 } & 2006 & 2010 & 2014 & $\begin{array}{c}\text { A or } \\
\text { above }\end{array}$ & BBB & BB & $\begin{array}{c}\text { B or } \\
\text { below }\end{array}$ \\
\hline Corporate nonfinancial & 28.0 & 31.1 & 33.0 & 48.0 & 42.2 & 5.1 & 4.6 \\
Mortgages & 10.3 & 9.4 & 9.7 & & & & \\
Agencies & 9.8 & 8.2 & 5.8 & 100.0 & 0.0 & 0.0 & 0.0 \\
Private placement & 6.8 & 7.2 & 7.3 & 37.5 & 50.5 & 5.9 & 4.5 \\
Other & 6.6 & 5.3 & 5.9 & 50.8 & 10.7 & 1.3 & 1.0 \\
CMBS & 6.5 & 4.8 & 3.5 & 90.9 & 7.7 & 0.9 & 0.6 \\
Foreign & 6.2 & 7.3 & 7.1 & 54.4 & 35.0 & 7.1 & 2.8 \\
Common stock & 4.8 & 4.2 & 3.9 & & & & \\
PLRMBS & 4.6 & 3.0 & 2.5 & 97.7 & 2.1 & 0.1 & 0.1 \\
Corporate financial & 3.2 & 2.2 & 1.7 & 95.5 & 3.0 & 1.5 & 0.0 \\
Cash & 2.7 & 2.9 & 2.6 & & & & \\
Other & 2.7 & 3.4 & 4.2 & & & & \\
ABS & 2.6 & 3.1 & 4.0 & 77.2 & 17.7 & 3.0 & 2.0 \\
Muni & 2.6 & 3.7 & 4.6 & 76.4 & 20.1 & 2.4 & 1.1 \\
Treasuries & 2.1 & 3.5 & 3.8 & 100.0 & 0.0 & 0.0 & 0.0 \\
Real estate & 0.6 & 0.6 & 0.6 & & & & \\
\hline \hline
\end{tabular}

Notes: The first three columns report the dollar share of assets in each category in 2006, 2010, and 2014. The next four columns show the within-category value-weighted share of assets in 2006 with NAIC designation of 1 (AAA/Aaa, AA/Aa, A/a), $2(\mathrm{BBB} / \mathrm{Baa}), 3(\mathrm{BB} / \mathrm{Ba})$, and 4 or below $(\mathrm{B} / \mathrm{B}, \mathrm{CCC} / \mathrm{Caa}$, in or near default). Agencies refer to Mortgage-Backed Securities and general obligation bonds issued by the Government-Sponsored Entities (GSEs). CMBS refers to Commercial MBS. Muni refers to U.S. municipal, U.S. state, and U.S. public utility bonds. PLRMBS refers to private-label residential MBS. ABS represents Asset-Backed Securities not included in Agency-MBS, PLRMBS, or CMBS. Treasuries include TIPS and STRIPs.

quantities than their holdings of Treasury and Agency securities. Municipal bonds constitute about $4 \%$ of insurers' portfolios.

The right panel of table 3 shows the within-category value-weighted share of assets in each NAIC designation as of 2006 for the debt securities reported on Schedule D. The non-governmental securities on insurers' balance sheets do not appear Treasury-like in their risk characteristics. A large share of insurers' holdings are in securities rated below A. For example, roughly half of insurers' corporate bond holdings are rated BBB or below. Similarly, even prior to the European sovereign crisis, insurers' holdings concentrated in riskier foreign bonds. Thus, risky assets dominate insurers' portfolios. ${ }^{13}$

\footnotetext{
${ }^{13}$ The small concentration of insurers' assets in U.S. Treasuries does not reflect constrained supply.
} 
Table 3 also demonstrates that insurers target illiquid assets. Corporate bonds, structured finance securities, and municipal bonds together comprise well over half of insurers' balance sheets. A large literature finds these securities trade infrequently and are subject to large transactions costs (Harris and Piwowar, 2006; Edwards, Harris, and Piwowar, 2007; Green, Hollifield, and Schürhoff, 2007; Bessembinder, Maxwell, and Venkataraman, 2013). There is virtually no secondary market for directly held commercial mortgages after origination (An, Deng, and Gabriel, 2011). This analysis echoes the conclusion of Hanson et al. (2015) who assign liquidity weights to different broad asset classes and find that commercial banks and life insurers have the most illiquid holdings. ${ }^{14}$ Furthermore, these asset classes feature predictable asset returns, a necessary condition for fluctations in $\omega$ to drive movements in the prices of assets traded in the open market unrelated to changes in their expected payoffs. ${ }^{15}$

\subsection{Insurers Purchase Assets With Low $\omega$}

As described in section 2.3, there are two complementary ways an insurer can try to target their purchases toward low $\omega$ assets. First, the insurer can look for assets with low $\bar{\omega}$. These assets can exist in equilibrium because the low $\bar{\omega}$ compensates the holder of the asset for high volatility of $\omega$ (De Long, Shleifer, Summers, and Waldmann, 1990). Second, the insurer can select assets experiencing temporary price dislocations, that is, with $\omega<\bar{\omega}$. We find evidence of insurers pursuing both strategies.

Insurers buy and hold low $\bar{\omega}$ assets. An insurer which buys a bundle of assets with $\bar{\omega}<1$ and holds these assets over time will reap the benefit of a portfolio of assets with low average $\omega$ without ever needing to know whether a particular asset has $\omega$ above or below its long run value. Thus, the empirical signature of targeting low $\bar{\omega}$ assets is long holding periods of illiquid assets. We have already discussed

We show in figure D.1 that the life insurance sector holds less than $2 \%$ of all Treasuries outstanding. The fraction of Treasuries held by insurers increases with maturity, but even at the long end of 20 to 30 years remaining to maturity the share held by insurers is below $14 \%$. This share is less than the insurance sector's share of the corporate bond market.

${ }^{14}$ We extend their methodology in Appendix E using our more granular data on insurer holdings.

${ }^{15}$ Gilchrist and Zakrajšek (2012) construct a component of aggregate corporate bond prices that does not predict future defaults. Greenwood and Hanson (2013) show that cyclical declines in issuer quality predict low investor returns. More broadly, Nozawa (2017) documents important variation in expected returns in the cross-section and time series of bonds. Breeden (1994), Gabaix, Krishnamurthy, and Vigneron (2007) and Boyarchenko, Fuster, and Lucca (2015) document a predictive relation between spreads and returns of MBS. More precisely, they focus on an option-adjusted spread (OAS) which adjusts for the possibility of prepayment and refinancing when rates drop. 
Table 4: Insurers are Long-hold Investors

\begin{tabular}{lccc}
\hline \hline & \multicolumn{3}{c}{ Years since purchase } \\
\cline { 2 - 4 } & 2006 & 2010 & 2014 \\
\hline Statistic: & 3.1 & 4.0 & 4.5 \\
Mean & 2.7 & 3.3 & 3.7 \\
SD & 0.5 & 0.5 & 0.6 \\
P(10) & 2.6 & 3.3 & 3.6 \\
P(50) & 6.5 & 8.0 & 9.8 \\
P(90) & 368,003 & 377,720 & 419,987 \\
Observations & Obes
\end{tabular}

Notes: The table reports summary statistics of the years since purchase for securities on insurers' balance sheets as of 2006, 2010, and 2014. The sample includes Schedule D holdings. Variables trimmed at 1st and 99th percentiles.

the illiquidity component. Table 4 shows that insurers have long holding periods. The table reports (value-weighted) summary statistics of the number of years since purchase for securities held by insurers at the end of 2006, 2010, and 2014. The mean time since purchase is about four years and the median is about 3 years. Thus, the typical security remains on an insurer's balance sheet for more than 6 years. These long holding periods allow insurers to earn the liquidity premia from buying low $\bar{\omega}$ assets and keeping them on their balance sheets for long periods.

Insurers buy assets experiencing temporary price dislocations. The second strategy involves identifying and buying assets with a temporarily low price, i.e. $\omega<$ $\bar{\omega}$. To assess whether insurers execute this strategy, we use the FINRA TRACE data set covering the universe of over-the-counter secondary market trades of corporate bonds over the period 2004-14 and examine the time path of bond prices around the date of an insurer purchase.

Table 5 presents evidence that bonds purchased by insurers earn positive abnormal returns over the subsequent 91 days. The table reports regressions of the form:

$$
\frac{P_{j, t+91}}{P_{j, t}}=\delta\left[i^{n s b u y_{j, t}}\right]+\Gamma X_{j, t}+\epsilon_{j, t},
$$

where $j$ indexes a corporate bond, $t$ is a day, insbuy $y_{j, t}$ takes a value of 1 if any insurer bought bond $j$ on date $t, X_{j, t}$ is a vector of characteristics of bond $j$ on date $t$, and $P_{j, t}$ is the ex-coupon clean price. We weight the regressions by the offering amount 
Table 5: Insurer Secondary Market Purchases

\begin{tabular}{|c|c|c|c|c|c|c|}
\hline & \multicolumn{6}{|c|}{ Dependent variable: $\frac{P_{j, t+91}}{P_{j, t}}$ (b.p.) } \\
\hline & (1) & (2) & (3) & (4) & (5) & (6) \\
\hline Right hand side variables: & & & & & & \\
\hline Insurer purchase indicator & $\begin{array}{c}60.9^{* *} \\
(18.2)\end{array}$ & $\begin{array}{c}33.6^{*} \\
(13.7)\end{array}$ & $\begin{array}{c}19.9^{*} \\
(7.6)\end{array}$ & $\begin{array}{c}18.5^{*} \\
(6.9)\end{array}$ & $\begin{array}{c}17.3^{*} \\
(7.0)\end{array}$ & $\begin{array}{c}18.5^{*} \\
(7.1)\end{array}$ \\
\hline 91 day lagged return & & & & & $\begin{array}{c}0.07^{+} \\
(0.04)\end{array}$ & $\begin{array}{c}0.06^{+} \\
(0.04)\end{array}$ \\
\hline Lagged ret. $\times$ Insurer purch. & & & & & & $\begin{array}{c}0.05^{* *} \\
(0.02)\end{array}$ \\
\hline Date FE & No & Yes & Yes & Yes & Yes & Yes \\
\hline Rating category FE & No & No & Yes & Yes & Yes & Yes \\
\hline Coupon, Coupon ${ }^{2}$ & No & No & Yes & Yes & Yes & Yes \\
\hline Duration-matched Treasury & No & No & Yes & Yes & Yes & Yes \\
\hline Maturity bin FE & No & No & No & Yes & Yes & Yes \\
\hline$R^{2}$ & 0.00 & 0.29 & 0.31 & 0.31 & 0.31 & 0.31 \\
\hline
\end{tabular}

Notes: The table reports coefficients from the regression $\frac{P_{j, t+91}}{P_{j, t}}=\delta i n s b u y_{j, t}+\Gamma X_{j, t}+\epsilon_{j, t}$. All columns contain 3,269,835 cusip-date observations from the period 2004-14 and are weighted by the offering amount of the bond. Standard errors clustered by calendar quarter in parentheses. $* *, *,+$ denotes statistical significance at the $1 \%, 5 \%$,and $10 \%$ levels.

of the bond and cluster standard errors by calendar quarter to reflect the 91 day return horizon. Column (1) includes no control variables in $X_{j, t}$. The coefficient of 60.9 means that in the 91 days following the purchase date, a bond purchased by an insurer earns a return 60.9 basis points higher (not annualized) than the typical 91 day bond return in the sample. Column (2) adds date fixed effects. The coefficient falls to 33.6, indicating that part of the overall return in column (1) comes from insurers timing their purchases. Nonetheless, more than half of the overall return appears to come from selecting which bonds to buy rather than when to purchase.

The next two columns show that controlling for observable characteristics of bonds bought by insurers reduces but does not eliminate the abnormal return result. As shown in Becker and Ivashina (2015), insurers buy higher coupon securities within a rating category. Column (3) controls for rating category fixed effects and the coupon in conjunction with the yield on a duration-matched Treasury at the bond's issuance. Controlling for these variables reduces the coefficient on purchase indicator, consistent with the Becker and Ivashina (2015) finding. The still-positive coefficient on in- 
Figure 2: Price Patterns of Insurers' Secondary Market Corporate Bond Purchases

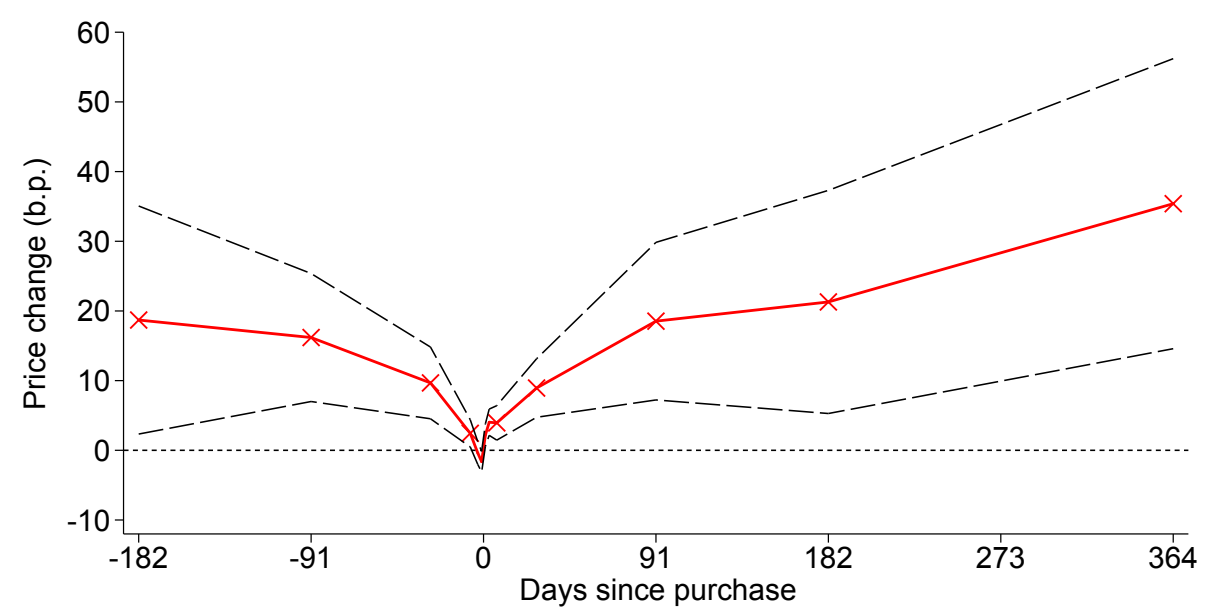

Notes: The figures plot the coefficients $\delta_{h}$ from the regression $\frac{P_{j, t+h}}{P_{j, t}}=\delta_{h}$ insbuy $y_{j, t}+\Gamma_{h} X_{j, t}+\epsilon_{j, h, t}$, where $i_{\text {insuy }}$ takes a value of 1 if an insurer bought bond $j$ on date $t$ and $X_{j, t}$ is a vector of bond characteristics including the coupon, the return on the duration-matched Treasury, categories of remaining maturity, the rating, and date fixed effects. The dashed lines indicate $90 \%$ confidence intervals on the point estimates for each horizon based on standard errors clustered by calendar quarter.

surer purchase in column (3) of 19.9, however, means that controlling for insurers' selection of risky, high coupon bonds does not fully explain the abnormal post-purchase returns. Column (4) further controls for insurers' choice of long duration securities by adding indicator bins for remaining maturity. Even with all of these controls, bonds purchased by insurers earn 18.5 basis point abnormal returns (t-statistic 2.68) over the subsequent 3 months relative to bonds purchased by other investor types on the same date.

We next show that some of the abnormal return comes from buying bonds which have recently dropped in price and experience a subsequent rebound, the empirical signature of a bond with $\omega_{j, t}<\bar{\omega}_{j}$. Figure 2 provides a visual representation of this result. The figure reports the coefficients and confidence intervals for the purchase indicator from repeating specification (13), including all of the control variables in column (4) of table 5, but varying the return horizon. The part of the figure to the left of 0 shows that bonds purchased by insurers have experienced abnormal price declines over the previous 3 months. Indeed, insurers appear to purchase bonds exactly at their price trough. The coefficient line for 91 days since purchase matches the coefficient in column (4). The more distant coefficients show that these bonds appear to earn positive abnormal returns past the 91 day horizon although we cannot reject equality of the 91 day and subsequent cumulative excess returns. 
The last two columns of table 5 show the effect of lagged returns more formally. The positive and marginally significant coefficient on the 91 day lagged return in column (5) provides evidence of pricing reversal of corporate bonds. In column (6) we allow the coefficient on the lagged return to vary with whether an insurer purchased the bond with the result that lagged performance has double the predictive effect for subsequent returns if the insurer buys the bond. Thus, not only do insurers select bonds which have recently declined in price, they appear able to discriminate across such bonds to find those most likely to rebound. Finally, while insurers use lagged returns to condition their purchases, their ability to select bonds with low $\omega$ goes beyond this criteria as evidenced by the still positive coefficient on insurer purchase even after controlling for lagged returns.

\subsection{Insurers Have Stable Liabilities}

Asset insulation requires stable sources of financing as a counterpart to holding assets with volatile $\omega$ for the long run. Figure 3 shows the steady rise of insurer liabilities over the period 2002-14, including during the crisis period of 2008-09. This steadiness reflects the long contractual horizon of life insurance policies and annuities and their ability to diversify mortality risk. While policy holders can request early termination of some policies in the form of a policy surrender and withdrawal, such surrenders impose a cost on the policy holder and did not spike during the crisis. ${ }^{16}$ Such liability stability is unusual in the financial sector; in a comparison of financial institutions, Hanson et al. (2015) find that life insurers have the longest contractual maturity and highest liability stickiness. Access to such a stable source of financing makes life insurers natural asset insulators.

\footnotetext{
${ }^{16}$ Surrender claims typically trigger a penalty if exercised in the first few years of a contract which then decays and may eventually disappear. In addition to surrenders, policies may lapse because of nonpayment of premiums, providing a windfall to the issuer (Gottlieb and Smetters, 2014). Ho and Muise (2011) report a small increase in combined lapses and surrenders in the 2007-09 period relative to previous years, almost entirely driven by lapses on newly issued policies. DeAngelo, DeAngelo, and Gilson $(1994,1996)$ discuss the possibility of coordination runs through surrenders. Foley-Fisher, Narajabad, and Verani (2016) discuss a run in 2007 on a particular type of debt issued by insurers called extendible funding agreement-backed notes (XFABN). They estimate that $40 \%$ of the total withdrawal of $\$ 18$ billion was due to a run, a small amount in comparison to insurers' total liabilities in 2007 and 2008 which exceeded $\$ 2.5$ trillion.
} 
Figure 3: General Account Liabilities of Life Insurers

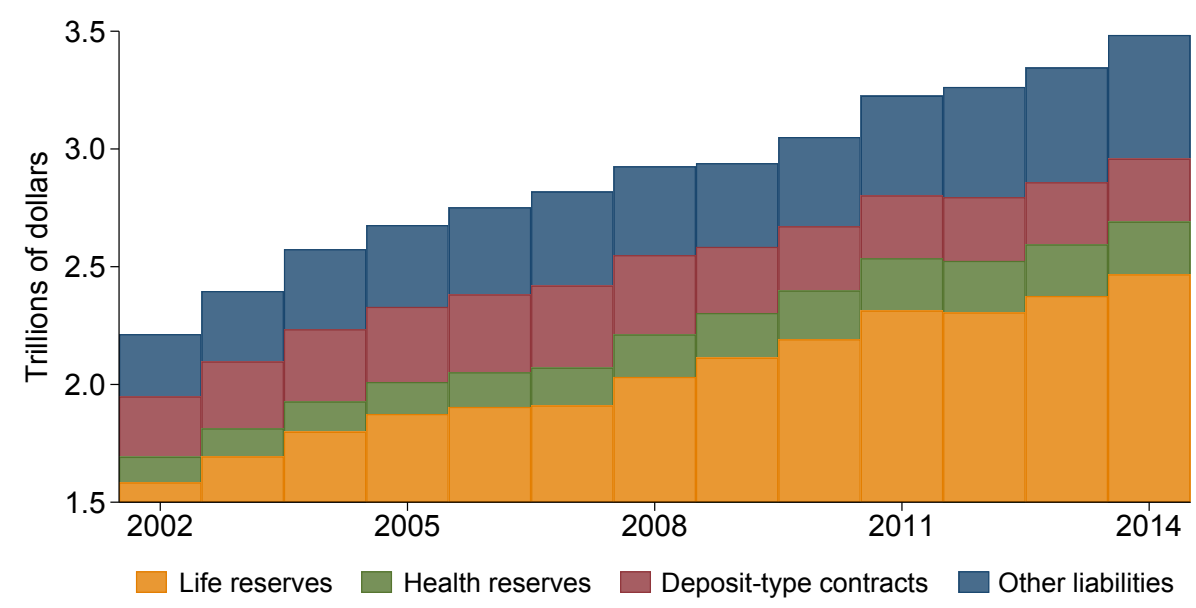

\section{Pass-through}

So far we have shown that life insurers manage their balance sheets in a manner consistent with the asset insulation view. We now exploit two unique features of the sector - detailed regulatory data and publicly-traded equity - to construct an especially informative metric to distinguish among alternative theories of intermediation: the pass-through of a dollar of assets to equity. We estimate a low pass-through out of the financial crisis, a higher pass-through during the crisis, and higher crisis passthrough for more distressed insurers. Of the theories we have considered, only the asset insulator theory can rationalize these moments.

We generalize notation in a straightforward way to accommodate multiple insurers and a more complicated liability structure. Let $E_{i, t}$ denote the market value of equity of insurer $i$ at date $t, A_{i, t}^{\text {out }}$ the open market gross asset value, and $L_{i, t}$ the present value of liabilities. We write the value of an insurer's equity as:

$$
E_{i, t}=A_{i, t}^{\text {out }}-L_{i, t}+[\text { Franchise value }]_{i, t} .
$$

Taking the total derivative of equation (14) and dividing through by lagged market equity:

$$
R_{i, t}^{E}=\rho_{t}^{A} R_{i, t}^{A}-\rho_{t}^{L} R_{i, t}^{L}+R_{i, t}^{O B},
$$

where $R_{i, t}^{E}$ denotes the return on market equity, $R_{i, t}^{m}$ the change in value of assets ( $m=A$, and we drop the out superscript to ease notation) or liabilities ( $m=L$ ) scaled 
by market equity, $\rho_{t}^{A}=1+\frac{\partial[\text { Franchise value }]_{i, t}}{\partial A_{i, t}^{\text {out }}}$ the pass-through with respect to assets,

$\rho_{t}^{L}=1+\frac{\partial[\text { [Franchise value }]_{i, t}}{\partial L_{i, t}}$ the pass-through with respect to liabilities, and $R_{i, t}^{O B}$ the scaled return to franchise value with respect to other variables. We seek to consistently estimate $\rho_{t}^{A}$. In our main approach we measure the pass-through $\rho_{t}^{A}$ of a dollar of assets using the cross-section of insurer portfolio corporate bond returns and equity returns on 2,600 trading days before, during, and after the financial crisis. In section 5.4 we use insurer-reported fair values of assets at the end of each year to confirm the basic patterns also hold at an annual frequency for a broader part of the balance sheet.

\subsection{Empirical Framework}

An identification challenge arises because the observed return on corporate bonds may be correlated with the changes in the value of other assets on insurers' balance sheets, of their liabilities, and of future business. For example, a decrease in the risk free rate would raise the value of both assets and liabilities. Our econometric procedure addresses this challenge by exploiting corporate bond returns which deviate substantially from their benchmark index. Specifically, we first partition $R_{i, t}^{A}$, the levered return on assets, into the part coming from corporate bonds for which we can construct a return, $R_{i, t}^{A}(T)$ ( $T$ for "traded"), and the remaining assets for which we do not know the return, $R_{i, t}^{A}(N T)$. Let $R_{i, t}^{A, x}$ denote the levered excess return over the bond's benchmark. We further partition $R_{i, t}^{A, x}(T)$ into the part coming from bonds with large abnormal (unscaled) returns $R_{i, t}^{A, x}(b), b \subseteq T$ ( $b$ for "big"), and the part coming from bonds without large abnormal returns $R_{i, t}^{A, x}\left(b^{c}\right), b^{c} \subseteq T \backslash b$. Our main specification takes the form:

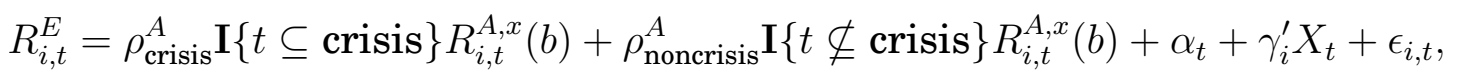

where crisis denotes the period from January 2008 to December 2009. Specification (16) estimates the pass-through $\rho^{A}$ separately for the crisis and non-crisis periods.

We construct $R_{i, t}^{A, x}(b)$ as follows. Data on bond prices come from the FINRA TRACE data set. TRACE reports the date, time, and transaction price of all over-the-counter trades of corporate bonds in the U.S. We form a daily price series for each bond using the last trade on each date and match the bonds by CUSIP to insurers' portfolio holdings. Let $P_{j, t}$ denote the (open market TRACE) price of bond $j, Q_{i, j, t-1}$ the quantity of bond $j$ held by insurer $i$, and $\tilde{R}_{j, t}^{A}=\frac{P_{j, t}-P_{j, t-1}}{P_{j, t-1}}$ the raw unscaled return based on the 
actual TRACE transaction prices. ${ }^{17}$ We match each bond by CUSIP to the Mergent database to obtain the current rating of the bond and the NAICS industry code of the issuer. We obtain the return on the BAML index of the same rating and the return on the ICE BAML index of the same industry (using a hand-constructed crosswalk) and compute the abnormal return $\tilde{R}_{j, t}^{A, x}$ as the residual in a pooled regression of the bond returns $\tilde{R}_{j, t}^{A}$ on the index returns, allowing the loadings to vary by rating-industry cell. A bond belongs to the large abnormal return set $b$ if $\tilde{R}_{j, t}^{A, x}$ exceeds 6 percentage points in absolute value. We then aggregate the large abnormal returns for each insurer to generate an insurer-level abnormal return on its corporate bond portfolio: $R_{i, t}^{A, x}(b)=\sum_{j \in b} s_{i, j, t-1} \tilde{R}_{j, t}^{A, x}$, where $s_{i, j, t} \equiv P_{j, t} Q_{i, j, t} / E_{i, t}$ denotes holdings of bond $j$ by insurer $i$ as a share of insurer $i$ 's market equity. ${ }^{18}$

We now discuss how equation (16) overcomes the identification challenge. First, the daily portfolio shock includes only those bond returns which deviate substantially from the return on bonds of similar industry and rating. If large returns reflect idiosyncratic movements in the particular bond rather than systematic characteristics targeted by the insurer for its portfolio, then they will be uncorrelated with other parts of the balance sheet or aspects of its business. Second, the shock includes only the part of the return on these bonds not explained by rating or industry. Therefore, factors common to all bond returns on a particular date do not affect estimation of the pass-through. Third, the date fixed effect $\alpha_{t}$ controls non-parametrically for macroeconomic shocks which affect all insurers equally. In particular, a rise in crossasset correlations during the financial crisis cannot explain the finding of a higher pass-through. Finally, the term $\gamma_{i}^{\prime} X_{t}$ allows insurers to load differently on aggregate factors contained in $X_{t}$ which might also correlate with their portfolio choices. In our baseline specification, $X_{t}$ contains the return on the 10 year Treasury bond and we allow the insurer-specific loadings to vary by year. This factor absorbs differences in duration mismatch across insurers which might also correlate with the duration of

\footnotetext{
${ }^{17}$ We exclude corrected or canceled trades, trades reported with delay, and trades which include a dealer commission. In order to have a current market value of each bond position, we require that the bond transact at least once on a date when an insurer reports the fair value price in a regulatory filing. Since we rely on actual transaction prices, we observe $\tilde{R}_{j, t}^{A}$ only on dates where the bond has transacted on consecutive trading days.

${ }^{18}$ Importantly, market participants could have constructed these portfolio returns in real time. The NAIC end-of-year filings of security holdings become public about two months after the end of the calendar year, and quarterly filings of transactions a few months after the end of the quarter. If insurers engaged in frequent turnover of their portfolios, then equity analysts and traders might not know which insurers experienced large abnormal portfolio returns on a particular date. However, in our data, the fraction of large abnormal bond returns occurring in positions which insurers had established before the previous regulatory filing exceeds $98 \%$ both in and out of the crisis.
} 
their assets.

In summary, cross-sectional differences in portfolio holdings and equity returns make possible identification of the pass-through. The identifying assumption is that $R_{i, t}^{A, x}(b)$ is uncorrelated with the returns on other parts of the insurer's balance sheet and with changes in the value of other business not captured by time fixed effects or the insurer-specific loadings.

\subsection{Attributes of Portfolio Shocks}

Before presenting our main results, we describe important aspects of the portfolio shocks which give the pass-through exercise power. First, insurers hold large positions in corporate bonds with volatile idiosyncratic returns. Therefore, large shocks to the (outside) value of the portfolio happen with sufficient frequency. Next, the portfolio shocks appear uncorrelated with other parts of insurers' balance sheets. Finally, the bond-level shocks decay substantially over time, implying a low pass-through for an investor with a long holding horizon.

Panel A of table 6 demonstrates the volatility of bond returns. Our sample contains more than 11 million observations of a bond held by an insurer for which we can calculate a daily abnormal return $\tilde{R}_{j, t}^{A, x}$. The standard deviation of abnormal returns in the whole sample is $2.6 \%$, with higher volatility during the crisis. Just over $1 \%$ of all bond returns satisfy our criterion for a large abnormal return. ${ }^{19}$ The rarity of such large returns gives a priori plausibility to the assumption that they do not reflect systematic variation in insurers' holdings. Nonetheless, the large number of total observations means we have more than 150,000 observations which qualify as large abnormal returns. The remainder of the table focuses on these observations.

The first three rows of Panel B describe the size of insurers' positions in these bonds relative to their market equity, $s_{i, j, t-1}$. The mean position in a bond experiencing a large abnormal return is $0.3 \%$ of an insurer's market equity with a standard deviation of $1.0 \% .5 \%$ of these returns occur in bonds where the insurer's initial position exceeds $1.4 \%$ of equity and the largest percentile of initial positions exceed $4 \%$ of the insurer's equity. These large positions reflect both concentrated asset portfolios and high leverage. The decline in insurer equity and concomitant rise in leverage in 2008 and 2009 explains why position sizes rise in the crisis.

The next set of rows report statistics for the total contribution of the bond return

\footnotetext{
${ }^{19}$ In fact, we choose the 6 p.p. threshold to ensure a ratio of large abornmal returns to total holdings of roughly $1 \%$. We have experimented with other thresholds and obtain similar results.
} 
Table 6: Portfolio Shock Summary Statistics

\begin{tabular}{|c|c|c|c|c|c|c|c|}
\hline \multirow[b]{2}{*}{ Variable } & \multirow[b]{2}{*}{ Symbol } & \multirow[b]{2}{*}{ Period } & \multirow{2}{*}{\multicolumn{2}{|c|}{ Mean SD }} & \multicolumn{2}{|c|}{ Abs. value } & \multirow[b]{2}{*}{ Obs } \\
\hline & & & & & P95 & P99 & \\
\hline & & \multicolumn{6}{|c|}{ Panel A: All returns } \\
\hline Bond abnorm. ret. (\%) & $\tilde{R}_{j, t}^{A, x}$ & All & 0.0 & 2.6 & 3.3 & 6.8 & 11452710 \\
\hline Bond abnorm. ret. (\%) & $\tilde{R}_{j, t}^{A, x}$ & Not crisis & -0.0 & 1.7 & 2.7 & 4.8 & 9373686 \\
\hline Bond abnorm. ret. (\%) & $\tilde{R}_{j, t}^{A, x}$ & Crisis & 0.1 & 5.1 & 6.0 & 12.9 & 2079024 \\
\hline & & \multicolumn{6}{|c|}{ Panel B: $\left|\tilde{R}_{j, t}^{A, x}\right|>6$} \\
\hline Position size (\%) & $s_{i, j, t-1}$ & All & 0.3 & 1.0 & 1.4 & 4.1 & 150831 \\
\hline Position size (\%) & $s_{i, j, t-1}$ & Not crisis & 0.2 & 0.5 & 0.9 & 2.5 & 46410 \\
\hline Position size (\%) & $s_{i, j, t-1}$ & Crisis & 0.4 & 1.2 & 1.7 & 4.9 & 104421 \\
\hline Contribution (b.p.) & $s_{i, j, t-1} \tilde{R}_{j, t}^{A, x}$ & All & 0.1 & 11.6 & 13.8 & 40.8 & 150831 \\
\hline Contribution (b.p.) & $s_{i, j, t-1} \tilde{R}_{j, t}^{A, x}$ & Not crisis & 0.1 & 4.9 & 7.8 & 22.1 & 46410 \\
\hline Contribution (b.p.) & $s_{i, j, t-1} \tilde{R}_{j, t}^{A, x}$ & Crisis & 0.1 & 13.6 & 16.6 & 48.9 & 104421 \\
\hline & & \multicolumn{6}{|c|}{ Panel C: Insurer-level } \\
\hline Insurer shock (b.p.) & $R_{i, t}^{A, x}(b)$ & All & 0.5 & 25.8 & 21.0 & 76.9 & 36831 \\
\hline Insurer shock (b.p.) & $R_{i, t}^{A, x}(b)$ & Not crisis & 0.1 & 6.1 & 9.5 & 28.4 & 29706 \\
\hline Insurer shock (b.p.) & $R_{i, t}^{A, x}(b)$ & Crisis & 2.0 & 57.2 & 74.3 & 204.1 & 7125 \\
\hline
\end{tabular}

to the (open market) value of the portfolio relative to equity, $s_{i, j, t-1} \tilde{R}_{j, t}^{A, x}$, equal to the product of the initial position and the abnormal return. While the mean portfolio impact is small, the standard deviation of the contribution is 11.6 b.p. and the largest (in absolute value) $1 \%$ of contributions exceed 40 b.p. Not surprisingly, more large contributions occur during the crisis, but many also occur outside the crisis period.

Panel $\mathrm{C}$ of table 6 shows that the large impacts of individual bonds aggregate to large insurer-level shocks. The standard deviation of the insurer portfolio shock $R_{i, t}^{A, x}(b)=\sum_{j \in b} s_{i, j, t-1} \tilde{R}_{j, t}^{A, x}$ exceeds 25 b.p. The relative magnitude of the variances of the insurer-level shocks and the individual contributions is informative. The passthrough methodology requires that the portfolio shocks occur independently of shocks to other parts of the insurer's balance sheet or other aspects of its business. We use only the abnormal part of the bond return and focus on the largest abnormal returns precisely to isolate plausibly independent bond-level shocks. If indeed the bond-level 
Figure 4: Portfolio Shocks by Date

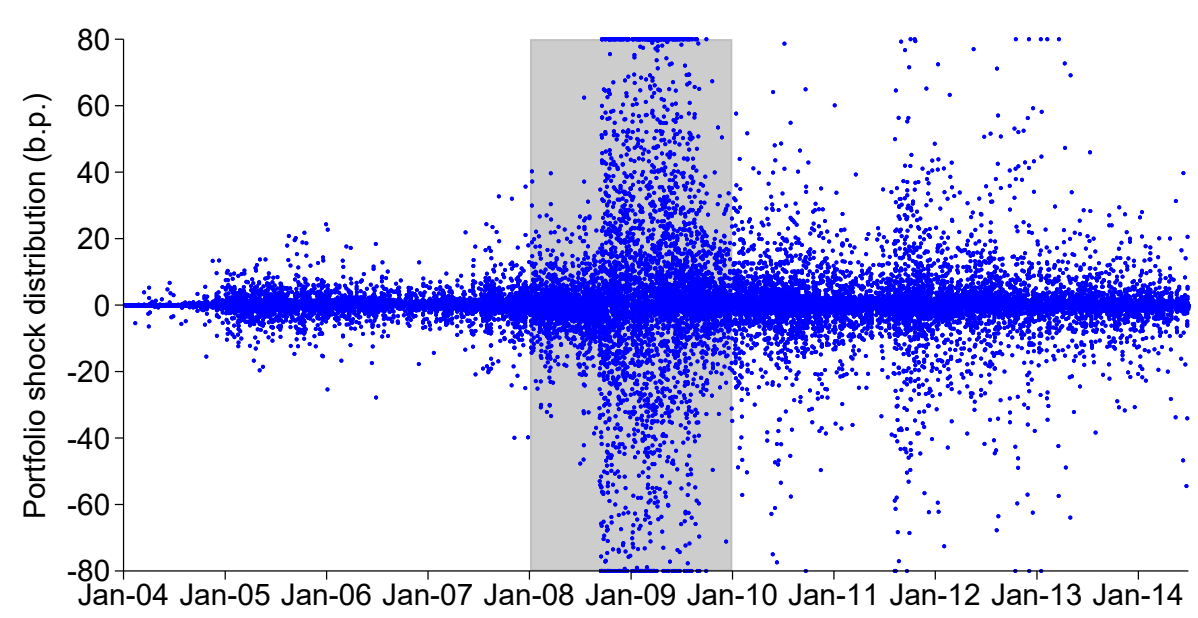

Each point in the figure shows the portfolio shock for one insurer-date. Shocks larger than 80 basis points in absolute value are top and bottom-coded for readability.

shocks are independent of each other, then the ratio of variances should equal the average number of bonds held by an insurer which experience a large abnormal return, whereas if the bond-level shocks to an insurer were perfectly correlated the ratio of variances would equal the square of the number of bonds experiencing a large abnormal return. In the data, the average number of holdings equals $4.1(150,831$ insurer-bond-date observations divided by 36,831 insurer-date observations) and the ratio of variances equals 4.9 , consistent with the independence assumption.

Figure 4 plots the distribution of the insurer-level portfolio shocks over time, with the gray shaded area demarcating the crisis period 2008-09. The figure shows the concentration of large shocks during the crisis period but also that large portfolio shocks occur before and especially after the crisis.

Table 7 provides further support for our identifying assumption that large idiosyncratic bond returns are uncorrelated with the rest of an insurer's balance sheet by comparing the large abnormal returns to the rest of the transacted portfolio. Column 1 reports the correlation coefficients of the (demeaned daily) unscaled large returns $\tilde{R}_{i, t}^{A, x}(b)=\sum_{j \in b} \frac{P_{j, t-1} Q_{j, t-1}}{\sum_{k \in b} P_{k, t-1} Q_{k, t-1}} \tilde{R}_{j, t}^{A, x}$ and small returns $\tilde{R}_{i, t}^{A, x}\left(b^{c}\right)=\sum_{j \notin b} \frac{P_{j, t-1} Q_{j, t-1}}{\sum_{k \notin b} P_{k, t-1} Q_{k, t-1}} \tilde{R}_{j, t}^{A, x}$ in and out of the crisis period. These correlations are less than 0.02 in absolute value. Column 2 compares the total scaled abnormal return $R_{i, t}^{A, x}(T)$ to the part coming from the large abnormal returns $R_{i, t}^{A, x}(b)$. Here we find coefficients close to albeit slightly above one, again consistent with idiosyncracy of the large abnormal returns. Furthermore, the similarity of coefficients in and out of the crisis period suggests that 
Table 7: Large Abnormal Returns Versus Other Parts of the Portfolio

\begin{tabular}{lcc}
\hline \hline & \multicolumn{2}{c}{ Dependent variable: } \\
\cline { 2 - 3 } & $\tilde{R}_{i, t}^{A, x}\left(b^{c}\right)$ & $R_{i, t}^{A, x}(T)$ \\
\cline { 2 - 3 } & $(1)$ & $(2)$ \\
\hline Right hand side variable: & & \\
$\tilde{R}_{i, t}^{A, x}(b) \times$ Not crisis & 0.0026 & \\
$\tilde{R}_{i, t}^{A, x}(b) \times$ Crisis & $(0.0036)$ & \\
$R_{i, t}^{A, x}(b) \times$ Not crisis & 0.020 & \\
$R_{i, t}^{A, x}(b) \times$ Crisis & $(0.024)$ & $1.19^{* *}$ \\
& & $(0.066)$ \\
Date FE & & $1.11^{* *}$ \\
Treasury factor & & $(0.12)$ \\
$R^{2}$ & Yes & Yes \\
Observations & Yes & 0.67 \\
\hline \hline
\end{tabular}

Notes: In column $1, \tilde{R}_{i, t}^{A, x}\left(b^{c}\right)$ is the insurer-level unscaled abnormal return on corporate bonds with small abnormal returns and $\tilde{R}_{i, t}^{A, x}(b)$ is the unscaled abnormal return on corporate bonds with large $(6$ p.p. or more) abnormal returns. Both variables are demeaned on each date and normalized to have unit variance in and out of the crisis such that the reported coefficients are correlations. In column 2 , $R_{i, t}^{A, x}(T)$ is the insurer-level abnormal return on all traded bonds and $R_{i, t}^{A, x}(b)$ is the abnormal return on bonds with large abnormal returns, with both variables scaled by the ratio of the holdings to market equity. The crisis is defined as January 2008-December 2009. Standard errors clustered by date in parentheses. ${ }^{* *}$ denotes statistical significance at the 1\% level. The data cover the period $2004-2014$.

differential correlation of large abnormal returns and the rest of the bond portfolio cannot explain a higher pass-through in the crisis.

Finally, figure 5 shows that these portfolio shocks substantially mean revert. The figure plots the coefficients from a regression of the bond-level, subsequent cumulative abnormal return over the horizon shown on the lower axis, $\tilde{R}_{j, t, t+h}^{A, x}$, on the abnormal return on the bond on date $t, \tilde{R}_{j, t-1, t}^{A, x}$, for a balanced sample of the large abnormal returns which contribute to the portfolio shocks. We weight the regressions by portfolio holdings of each bond. Some of the mean reversion occurs fairly quickly, within a week of the shock. A substantial part occurs at lower frequency. By the two year horizon, two-thirds of the typical shock has dissipated. Thus, an investor able to hold a bond for two years past a large abnormal return can expect two-thirds of that return 
Figure 5: Reversion of Large Abnormal Bond Returns

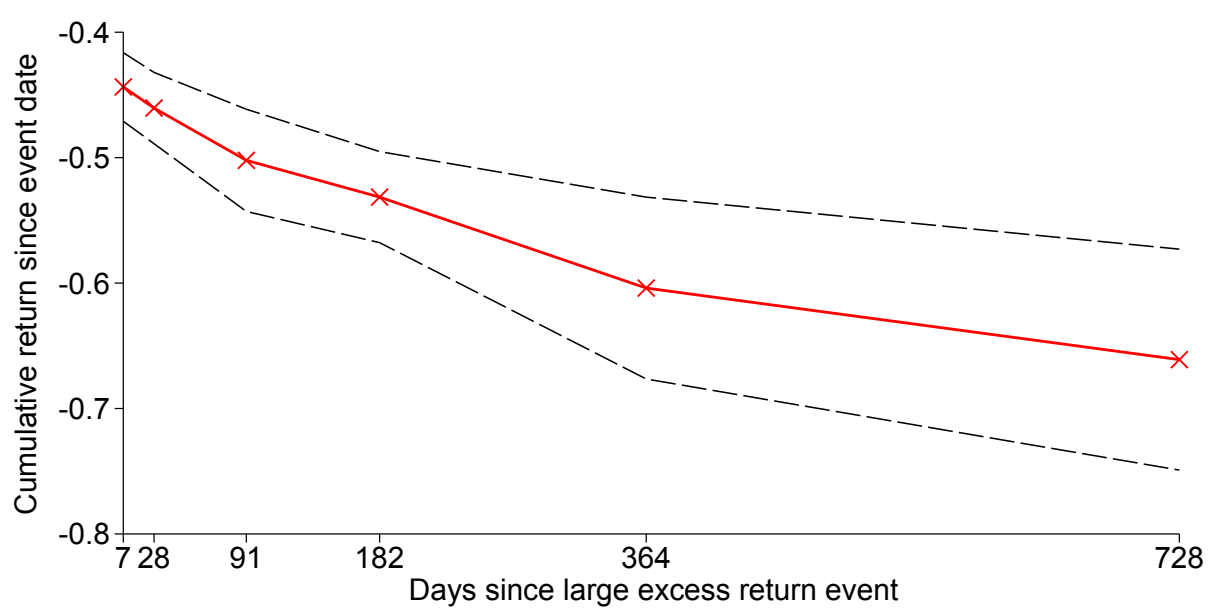

Notes: The figures plot the coefficients $\delta_{h}$ from the regression $\tilde{R}_{j, t, t+h}^{A, x}=\delta_{h, 0}+\delta_{h} \times \tilde{R}_{j, t-1, t}^{A, x}+\epsilon_{j, t, t+h}$, where $\tilde{R}_{j, t, t+h}^{A, x}$ denotes the excess return of bond $j$ between dates $t$ and $t+h$. The dashed lines indicate $90 \%$ confidence intervals on the point estimates for each horizon based on standard errors two-way clustered by CUSIP and calendar quarter.

to eventually reverse itself. ${ }^{20}$

\subsection{Results}

Table 8 presents our main finding. Column 1 reports our baseline specification of the equity return regressed on the scaled abnormal bond return $R_{i, t}^{A, x}(b)$, controlling only for the date fixed effects and the general movement in interest rates by including in $X_{t}$ the return on the 10-year Treasury and allowing the coefficient to vary across insurers and by year. We obtain a pass-through of 0.15 out of the crisis and 1.10 during the crisis. The table reports standard errors clustered by date to allow for arbitrary correlation across insurers on each date. We can reject equality of the passthrough coefficients and equality of the pass-through out of the crisis and unity at the 1 percent level. We cannot reject that pass-through during the crisis equals one at any conventional confidence level. In words, an additional dollar of assets translates into an additional $\$ 0.15$ of equity out of the crisis, but slightly more than $\$ 1$ of equity during the crisis. Column (2) shows that pass-through into the value of public debt

\footnotetext{
${ }^{20}$ The long-run mean reversion is slightly higher for large abnormal returns during the crisis, possibly reflecting a higher share of $\omega$-type fluctuations due to the disruption in markets during that period. However, even out of the crisis the long-run reversion exceeds one-half. Moreover, a rising share of fluctuations due to $\omega$ during the crisis would bias our results away from finding a rising pass-through.
} 
Table 8: Estimates of Pass-through of Abnormal Bond Returns

\begin{tabular}{lcc}
\hline \hline & \multicolumn{2}{c}{ Dependent variable: } \\
\cline { 2 - 3 } & Equity & Debt \\
\cline { 2 - 3 } \multicolumn{2}{c}{$(1)$} & $(2)$ \\
\hline Large excess bond returns interacted with: & \\
Not crisis & 0.15 & -0.02 \\
& $(0.21)$ & $(0.10)$ \\
Crisis & $1.10^{* *}$ & $0.33^{*}$ \\
& $(0.32)$ & $(0.17)$ \\
\hline Date FE & Yes & Yes \\
Dep. var. winsorized & Yes & Yes \\
Treasury factor control & Yes & Yes \\
$R^{2}$ & 0.56 & 0.59 \\
p(Homog. effect) & 0.013 & 0.069 \\
Observations & 36,831 & 13,149 \\
\hline \hline
\end{tabular}

Notes: The estimating equation is: $R_{i, t}^{E}=\rho_{\text {crisis }}^{A} \mathbf{I}\{t \subseteq \operatorname{crisis}\} R_{i, t}^{A, x}(b)+\rho_{\text {noncrisis }}^{A} \mathbf{I}\{t \not \subset$ crisis $\} R_{i, t}^{A, x}(b)+\alpha_{t}+$ $\gamma_{i}^{\prime} X_{t}+\epsilon_{i, t}$, where $R_{i, t}^{E}$ denotes the equity return and $R_{i, t}^{A, x}(b)$ the market-capitalization scaled return on the insurer's holdings of corporate bonds with abnormal returns greater than 6 p.p. $X_{t}$ includes the return on the 10 year Treasury bond and we allow $\gamma_{i}$ to vary by calendar year. The dependent variable is winsorized each month at the median \pm 2.5 standard deviations. Standard errors clustered by date are reported in parentheses. $* *$ and $*$ denote statistical at the 1 and $5 \%$ levels. The data cover the period $2004-2014$.

exhibits a similar pattern. ${ }^{21}$

Robustness. Table 9 establishes the robustness of the basic pattern of a low passthrough out of the crisis and a higher pass-through during the crisis, focusing on the equity response. The first row repeats our baseline specification. Rows 2-5 show the basic pattern remains robust to expanding the amount of variation used in the regression. Row 2 removes the Treasury factor control and row 3 additionally removes the date fixed effects. The regression coefficients change little without the Treasury factor control and rise slightly without the date fixed effects, indicating that many

\footnotetext{
${ }^{21}$ The sample in column 2 is restricted to insurers with liquid CDS on their outstanding public debt throughout our sample period. The tickers of these insurers are: AFL, ALL, LNC, MET, PRU, TMK. To compute the return on public debt, we first use Compustat and Mergent FISD to construct the maturity structure of public debt for each company. We then use the CDS yield curve from Markit to price the debt using a no-arbitrage condition. The equity pass-through is lower for this subgroup so that pass-through on the total value of the firm is not higher.
} 
macroeconomic confounding factors such as interest rate or overall market changes are already accounted for in the construction of the abnormal returns. In row 4 we use the raw rather than the winsorized equity return as the dependent variable, with the result that the standard errors roughly double. In row 5 we construct the portfolio shock using all (i.e. not only large) abnormal bond returns. Here the standard errors shrink substantially while the point estimates do not change much, indicating that our baseline approach of restricting to only large abnormal bond returns yields conservative inference. This specification also provides one piece of evidence against an inattention interpretation of the low pass-through out of the crisis, as including all abnormal bond returns in the construction of the portfolio shocks yields a shock standard deviation out of the crisis of 23 basis points.

The next rows more tightly restrict the variation, in row 6 by allowing the loadings used to construct abnormal bond returns to vary by year, in row 7 by constructing bond returns at the issuer (rather than issue) level, and in row 8 by including insurerspecific loadings on the three Fama-French factors in $X_{t}$. Rows 9 and 10 explore sensitivity to the large declines in equity during the crisis for some insurers, in row 9 by including the interaction of the inverse of market capitalization and a date fixed effect and in row 10 by scaling the changes in equity and bond holdings by the sample mean of market capitalization for each insurer rather than the $t-1$ market capitalization. Row 11 defines the crisis period more narrowly as the one year period from September 2008 to August 2009. We obtain similar results in these specifications to the baseline.

Rows 12-18 trim the sample along various dimensions. Row 12 restricts the sample to dates on which at least one insurer experiences a portfolio shock larger than $0.1 \%$ of their equity. Restricting the variation to coming from large shocks provides another way of assessing whether inattention to small shocks drives the low passthrough coefficients out of the crisis. While the number of observations falls by roughly half, there is almost no change in the pass-through coefficients. To interpret the stability of coefficients in row 12 , it helps to recall the OLS identity that the coefficient estimated on a full sample is equal to a weighted average of the coefficients estimated on separate sub-samples where the weights are the contributions from each sample to the total variance of the regressors. Thus, even in the full sample the pass-through coefficients overwhelmingly reflect the pass-through from large shocks. Similarly, the row 13 sample only includes dates on which the absolute value of the return on the aggregate stock market exceeds $1 \%$, as investors might pay particular attention to portfolio performance on days in which the overall market exhibits 
Table 9: Pass-through Robustness

\begin{tabular}{lcccccc}
\hline \hline Specification & $\rho_{\text {noncrisis }}^{A}$ s.e. & $\rho_{\text {crisis }}^{A}$ & s.e. & \multicolumn{2}{c}{$p\left(\rho_{\text {crisis }}^{A}=\right.$ Oboncrisis } \\
& 0.15 & 0.21 & 1.10 & 0.32 & 0.013 & 36,831 \\
\hline 1. Baseline & 0.12 & 0.21 & 1.03 & 0.32 & 0.017 & 37,394 \\
2. No Treasury factor control & 0.25 & 0.47 & 1.67 & 0.34 & 0.014 & 37,395 \\
3. No controls & 0.11 & 0.37 & 1.85 & 0.72 & 0.032 & 36,831 \\
4. Dep. var. not winsorized & 0.04 & 0.07 & 0.85 & 0.21 & 0.000 & 36,831 \\
5. All abnormal bond returns & 0.14 & 0.21 & 1.13 & 0.35 & 0.015 & 36,831 \\
6. Time-varying loadings & 0.20 & 0.29 & 1.04 & 0.33 & 0.057 & 36,831 \\
7. Issuer return & 0.11 & 0.17 & 0.98 & 0.34 & 0.021 & 36,831 \\
8. Fama-French factors control & -0.02 & 0.21 & 1.09 & 0.37 & 0.010 & 36,816 \\
9. Size control & 0.15 & 0.18 & 0.89 & 0.41 & 0.099 & 36,816 \\
10. Alternative denominator & 0.23 & 0.27 & 1.19 & 0.34 & 0.028 & 36,831 \\
11. Crisis period 9/1/08-8/31/09 & 0.16 & 0.22 & 1.11 & 0.32 & 0.015 & 17,667 \\
12. Dates with shock $>10$ b.p. & 0.17 & 0.43 & 1.16 & 0.53 & 0.147 & 10,170 \\
13. | $R_{t}^{\text {mkt }} \mid>1$ p.p. & 0.17 & 0.21 & 1.04 & 0.31 & 0.021 & 26,646 \\
14. $R_{t}^{\text {mkt }} \mid<1$ p.p. & 0.05 & 0.21 & 1.00 & 0.44 & 0.053 & 36,486 \\
15. Shocks $<$ 80 b.p. & 0.11 & 0.21 & 0.92 & 0.80 & 0.332 & 33,666 \\
16. Drop crisis timeline dates & 0.21 & 0.21 & 1.01 & 0.37 & 0.059 & 35,577 \\
17. Drop FOMC dates & 0.11 & 0.22 & 1.10 & 0.32 & 0.010 & 23,220 \\
18. Drop pre-crisis & 0.22 & 0.39 & 1.19 & 0.37 & 0.071 & 36,787 \\
19. 3 day return & 0.38 & 0.53 & 1.65 & 0.82 & 0.192 & 36,893 \\
20. 7 day return & & & & & &
\end{tabular}

Notes: The estimating equation is: $R_{i, t}^{E}=\rho_{\text {crisis }}^{A} \mathbf{I}\{t \subseteq \operatorname{crisis}\} R_{i, t}^{A, x}(b)+\rho_{\text {noncrisis }}^{A} \mathbf{I}\{t \not \subseteq$ crisis $\} R_{i, t}^{A, x}(b)+\alpha_{t}+$ $\gamma_{i}^{\prime} X_{t}+\epsilon_{i, t}$, where $R_{i, t}^{E}$ denotes the equity return and $R_{i, t}^{A, x}(b)$ the market-capitalization scaled return on the insurer's holdings of corporate bonds. Each row reports the results from a separate regression. Row 1 reproduces the baseline result. Each subsequent row modifies the baseline. In row $2 X_{t}$ is empty. In row $3 X_{t}$ is empty and $\alpha_{t}$ is omitted from the regression. In row 4 the dependent variable is not winsorized. In row 5 the portfolio shock is computed without excluding small abnormal bond returns. In row 6 the abnormal bond returns are constructed using rating and industry loadings allowed to vary by year. Row 7 uses bond returns aggregated by issuer. In row $8 X_{t}$ additionally includes the three Fama-French factors. In row $9 X_{t}$ includes an interaction of a date fixed effect with the inverse of insurer market capitalization. In row $10 R_{i, t}^{E}$ and $R_{i, t}^{A, x}(b)$ are rescaled by the ratio of one-day lagged market capitalization to the insurer's sample mean market capitalization. Row 11 shrinks the crisis period. Row 12 only includes dates with a portfolio shock of at least 10 b.p. in absolute value. Row 13 only includes dates where the absolute value of the return on the Russell 3000 exceeds 1 p.p. while row 14 excludes these dates. Row 15 drops shocks larger than 80 b.p. Row 16 drops any date included on the St. Louis Fed crisis timeline. Row 17 drops any date which coincides with an FOMC meeting. Row 18 drops observations before 2008. Rows 19 and 20 report the baseline specification for a 3 and 7 day horizon, with excess return threshold increased to 8 p.p. and 10 p.p., respectively. Standard errors clustered by date. $* *$ and $*$ denote statistical at the 1 and $5 \%$ levels. The data cover the period 2004 2014. 
large movements. However, while the standard errors rise in this smaller sample, the point estimates of pass-through in and out of the crisis remain almost unchanged.

Rows 14 to 16 instead restrict the variation to coming from smaller shocks. In row 14 we exclude dates on which the overall market moved more than $1 \%$, in row 15 we drop the roughly 350 portfolio shocks larger than 80 b.p., and in row 14 we drop any date identified on the St. Louis Fed crisis timeline. ${ }^{22}$ While the standard error of the crisis pass-through rises in rows 15 and 16, all of the coefficients remain close to their baseline values. Row 17 removes dates with a Federal Reserve Open Market Committee meeting or announcement as bond price changes on these data are especially likely to reflect changes in interest rates. Row 18 drops observations from before 2008, showing that pass-through falls back to a low level after 2009.

Finally, rows 19 and 20 explore the sensitivity of our results to the window over which we estimate the pass-through. In row 19 we estimate the pass-through over a 3-day horizon and in row 20 we estimate the pass-through over a 7-day horizon. Since the variance of returns may increase with horizon, we raise the threshold for inclusion in the idiosyncratic component $b$ to 8 p.p. for the 3-day horizon and to 10 p.p. for the 7-day horizon. The pass-through out of the crisis remains low as the horizon increases, while the pass-through in the crisis remains above 1.

The evidence of differential pass-through in and out of the crisis also does not depend on the asset price behavior of only a few insurers. To make this point, we selectively drop three insurers at a time, or $20 \%$ of our sample, and re-estimate the baseline regression in column 1 of table 8 . Figure 6 reports the histogram of coefficients from these $\frac{15 !}{12 ! 3 !}=455$ regressions. Most coefficients cluster around the level estimated in the baseline specification in the full sample and the two distributions of coefficients in and out of the crisis do not overlap. The gap between the crisis and out of crisis coefficients estimated for each sample ranges between 0.5 and 1.4.

Heterogeneity. The asset insulator theory explains the higher pass-through during the crisis as reflecting the heightened risk of liquidation. We find additional evidence of this channel by splitting the sample according to the level of financial distress. Specifically, we form two subgroups of insurers based on each insurer's stock return during the period September 12, 2008 to October 10, 2008. This four-week period begins with the day of the Lehman bankruptcy and contains the most acute drop in insurer stock prices in our sample. To avoid a mechanical correlation between stock

\footnotetext{
22These are available at https://www.stlouisfed.org/financial-crisis/full-timeline. We thank our discussant Ralph Koijen for suggesting this last sample filter and providing us with a data set of the timeline dates.
} 
Figure 6: Pass-through Sample Robustness

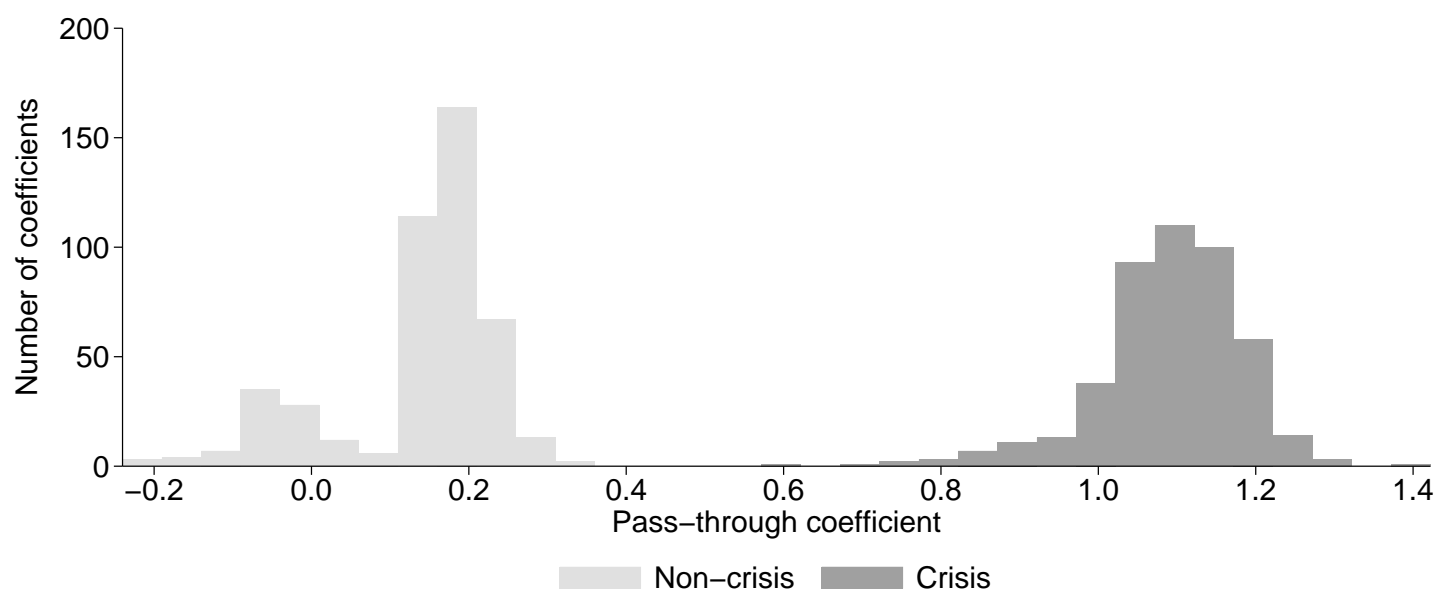

Notes: The figure reports the histogram of coefficients of pass-through in and out of the crisis from the regression specification in column (1) of table 8 when we exclude three insurers at a time from the sample. The crisis period is January 2008-December 2009. The data cover the period 2004 - 2014.

price decline and crisis pass-through from sorting based on decline, we then drop this four-week period from the sample. Table 10 reports the results from estimating equation (16) separately for each subsample. The pass-through coefficient rises during the crisis in both groups, consistent with the increase in the comparative advantage of an asset on the balance sheet playing a role and with a heightened level of distress even among the healthier insurers. However, the pass-through coefficient for the healthier subgroup rises by only half as much as for the more distressed subgroup. The limited sample size generates too little power to formally reject equality of the crisis passthrough coefficients at conventional levels, but the difference of 0.6 is consistent with liquidation risk substantially raising the pass-through.

\subsection{Annual Pass-through}

An exercise based on regulatory data reported at the end of each calendar year complements the previous results. These data have the advantage of much fuller coverage of assets, but at the cost of limited power as we have one observation per insurer-year. The annual data do allow us to exploit variation by insurer in broad asset class allocation as well as within asset class returns. Indeed, as we document in figure E.1, insurers differ substantially in their broad asset class allocation with some heavily exposed to ABS and PLRMBS before the crisis and others with virtually no exposure.

We construct annual portfolio returns from the NAIC regulatory data. NAIC 
Table 10: Pass-through by Insurer Distress

\begin{tabular}{lcc}
\hline \hline & \multicolumn{2}{c}{ Dependent variable: equity return } \\
\cline { 2 - 3 } & $\begin{array}{c}\text { Equity return } \\
09 / 12 / 08-\end{array}$ & $\begin{array}{c}\text { Equity return } \\
09 / 12 / 08-\end{array}$ \\
Sample: & $\begin{array}{c}10 / 10 / 08 \\
\text { Median }\end{array}$ & $\begin{array}{c}10 / 10 / 08> \\
\text { Median }\end{array}$ \\
\cline { 2 - 3 } & $(1)$ & $(2)$ \\
\cline { 2 - 2 } & & \\
Large excess bond returns interacted with: & & \\
Not crisis $\times$ Large bond returns / market cap & 0.32 & 0.05 \\
& $(0.31)$ & $(0.22)$ \\
Crisis $\times$ Large bond returns / market cap & $1.09^{* *}$ & 0.49 \\
& $(0.37)$ & $(0.41)$ \\
\hline Date FE & Yes & Yes \\
Drop 09/15/08-10/10/08 & Yes & Yes \\
Dep. var. winsorized & Yes & Yes \\
Treasury factor & Yes & Yes \\
P(Crisis pass-through equal) & 0.358 & 0.358 \\
$R^{2}$ & 0.62 & 0.59 \\
Observations & 17,161 & 19,346 \\
\hline \hline
\end{tabular}

Notes: The table shows the extent to which pass-through differs by how much the insurer's stock fell in the period September 12, 2008 - October 10, 2008. The crisis period is January 2008-December 2009. Standard errors clustered by date in parentheses. ** denotes statistical significance at the $1 \%$ level. The data cover the period 2004 - 2014 excluding the period September 12, 2008 - October 10, 2008.

Schedules BA and D require insurers to report a fair value per unit for all securities held on their balance sheet on December 31st of each year, regardless of whether valuation of the assets occurs at fair value or historical cost for accounting and regulatory purposes. These schedules also list the value of dividends received during the year, pre-payments, and purchases and sales. We use this information to construct for each asset a total dollar gain equal to the sum of mark-to-market capital gains and net dividends. Summing over assets then gives the total dollar value of investment gains and losses in a year. We obtain information on derivatives holdings from Schedule DB. Like bonds, insurers must include a fair value of each derivative position in their filing, but depending on the hedging classification may not include unrealized gains and losses in their accounting totals. We use a string matching algorithm to match open derivatives positions across consecutive filing years and the fair value re- 
Table 11: Annual Portfolio Return Pass-through

\begin{tabular}{|c|c|c|c|c|}
\hline & \multicolumn{4}{|c|}{ Dependent variable: stock return } \\
\hline & \multicolumn{4}{|c|}{ Portfolio capital gains measured as: } \\
\hline & & \multicolumn{2}{|c|}{ Excess return w.r.t.: } & \multirow[b]{2}{*}{$\begin{array}{l}\text { Actual incl. } \\
\text { derivatives }\end{array}$} \\
\hline & Actual & $\begin{array}{l}\text { Asset-class } \\
\text { year mean }\end{array}$ & 1 factor & \\
\hline & (1) & (2) & (3) & (4) \\
\hline \multicolumn{5}{|c|}{ Right hand side variables: scaled portfolio return in: } \\
\hline Not crisis & $\begin{array}{c}-0.047 \\
(0.036)\end{array}$ & $\begin{array}{l}-0.33^{* *} \\
(0.11)\end{array}$ & $\begin{array}{c}-0.48^{* *} \\
(0.15)\end{array}$ & $\begin{array}{c}-0.029 \\
(0.042)\end{array}$ \\
\hline 2008 & $\begin{array}{r}0.72^{*} \\
(0.29)\end{array}$ & $\begin{array}{r}0.77^{*} \\
(0.33)\end{array}$ & $\begin{array}{c}0.71 \\
(0.50)\end{array}$ & $\begin{array}{c}0.87^{+} \\
(0.51)\end{array}$ \\
\hline 2009 & $\begin{array}{c}0.022 \\
(0.052)\end{array}$ & $\begin{array}{c}0.31 \\
(0.42)\end{array}$ & $\begin{array}{c}0.86 \\
(0.93)\end{array}$ & $\begin{array}{c}0.022 \\
(0.050)\end{array}$ \\
\hline Year FE & Yes & Yes & Yes & Yes \\
\hline$R^{2}$ & 0.55 & 0.55 & 0.56 & 0.54 \\
\hline Observations & 150 & 150 & 150 & 150 \\
\hline
\end{tabular}

Notes: The table presents the coefficients from regressions of the insurance company's total stock return on the change in the value of its asset holdings. The right hand side variable is the total return on the insurer's asset portfolio. In column (2), we adjust the portfolio capital gains by removing the asset-class mean in each year before aggregating to the individual insurer level. We provide details on our asset class definitions in the online appendix. In column (3), we control for differences across insurers in initial holdings by extracting the first principal component for each asset class before aggregating to the individual insurer level. In column (4), we include derivative positions in addition to the securities held. Heteroskedasticity-robust standard errors in parentheses. **, *, and + denote statistically significant at the 1, 5, and 10\% levels. The data cover the period $2004-2014$.

ported in each year to construct mark-to-market gains and losses on the derivatives portfolio. ${ }^{23}$ Our measure differs, sometimes substantially, from the investment gains and losses reported by insurers in their statutory filings because it attributes gains and losses to the period in which the underlying investments change value rather than the year in which they are recognized for accounting purposes.

Table 11 reports regressions of the same form as equation (16) but using the NAIC data at the annual frequency. The specification in column 1 includes no controls other

\footnotetext{
${ }^{23}$ The annual filings also contain detailed data on wholly owned mortgages (Schedule B) and directly held real estate (Schedule A), but value these assets only at historical cost. We exclude these assets in our calculations.
} 
than the year fixed effects and reports pass-through with respect to the scaled return on the portfolio assets. We obtain a coefficient of 0.72 for the year 2008 and of essentially zero for all other years. In columns 2 and 3 we construct abnormal portfolio returns by first demeaning each asset class return with respect to its yearly mean across all insurers (column 2) or as the residual after extracting one asset-class specific factor as chosen by the Bai (2009) interactive effects factor model (column 3). The 2008 pass-through changes little, while the non-crisis pass-through falls to be a bit negative. ${ }^{24}$ The 2009 pass-through increases in these specifications. In column 4 we augment the Schedule D and BA holdings with the mark-to-market capital gain/loss on each insurer's derivatives portfolio. The pass-through coefficients change little, in part because the gains and losses on the non-derivatives holdings dwarf those from the derivatives portfolio. In sum, while less powerful and well-identified than the results based on daily returns, annual data confirm the basic result of a low passthrough out of the crisis and a higher pass-through during the crisis.

\subsection{Discussion}

The finding of a pass-through coefficient significantly below one out of the crisis poses a challenge to a Modigliani-Miller theory of the firm and to the other standard theories of financial institutions. The asset insulator view of insurers can explain both the low pass-through out of the crisis and the increase in pass-through during the crisis. In normal conditions, as asset prices fluctuate on the market, the value inside the firm is preserved and the pass-through is low. When the crisis occurs, asset prices on the market drop. This results in a larger comparative advantage to holding the assets on the balance sheet, so franchise value increases. However, this effect is mitigated by the deterioration in the financial health of insurers, putting them closer to liquidation. Assets are less likely to be held for a long time, and therefore less well insulated from market movements, which results in a higher pass-through. Further, while high, the value creation from the asset insulation activity is precarious. Adverse price changes can precipitate liquidation, further increasing the pass-through.

Still, while the asset insulator theory predicts a pass-through in normal times below one, point estimates in the range of $\$ 0.10$ to $\$ 0.20$ may seem low. We offer three comments in this regard.

\footnotetext{
${ }^{24}$ In interpreting the negative coefficients, recall that while more comprehensive than the set of corporate bonds which transact on consecutive days, the annual filings nonetheless lack mark-to-market prices of directly held mortgages, real estate, assets held outside the insurance company, and, especially, liabilities.
} 
First, the crucial predictions of the insulator theory are that the pass-through in normal times is below one and that it rises during the crisis. In almost all specifications, the data reject at conventional confidence levels both equality of the out-of-crisis pass-through and one and equality of the coefficients in and out of the crisis, confirming the predictions of the theory. However, the $95 \%$ confidence interval in our baseline specification does not reject a pass-through out of the crisis of as high as $\$ 0.56$.

Second, valuation conventions of equity analysts of insurance companies comport with a low pass-through in normal times. According to Nissim (2013), most equity analysts value insurance companies using a price-book ratio which excludes accumulated other comprehensive income (AOCI) from the book valuation. Our own conversations with market participants confirm the popularity of this approach. The category AOCI includes all of the unrealized gains and losses from the asset portfolio. Nissim (2013, p. 326) describes the rationale for excluding AOCI as stemming from a desire to smooth the high volatility of investment gains and losses, consistent with the asset insulator view. In our language, the industry practice of ignoring AOCI when doing valuation amounts to a target pass-through of close to zero in normal conditions.

Third, our theory abstracts from other frictions which might amplify the asset insulation function in non-crisis periods. Monitoring costs, rational inattention, and heuristics provide possible candidates. For example, if equity market participants must pay a cost to monitor developments on insurers' portfolios, they will do so only if the mis-valuation from not paying the cost exceeds the cost itself. With a target passthrough absent information costs already low, the gains from monitoring are small and participants will not pay the cost, pushing the realized pass-through even lower. Similarly, with low target pass-through, valuing assets strictly at book value may be preferred to valuing strictly at market value. On the other hand, the similarity of pass-through coefficients on volatile and tranquil trading days militates against putting too much emphasis on amplification channels which rely on inattention.

In sum, the pass-through evidence in and out of the crisis, and the cross-sectional differences in pass-through during the crisis, accord well with the asset insulator view of life insurers. In contrast, the financial friction view cannot explain the low passthrough out of the crisis, while the policy guarantee view counterfactually predicts a smaller pass-through during the crisis and for more distressed insurers. We conclude that only the asset insulator view of life insurers can rationalize the empirical passthrough moments. ${ }^{25}$

\footnotetext{
${ }^{25}$ We have discussed already the inconsistency of the liability matching view with insurers' portfolio
} 
Stock return

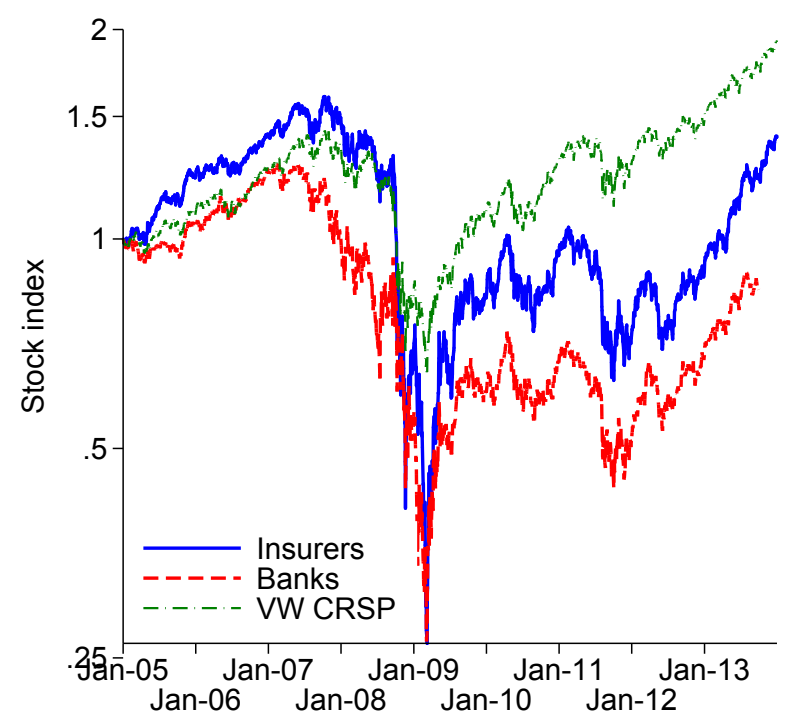

CDS

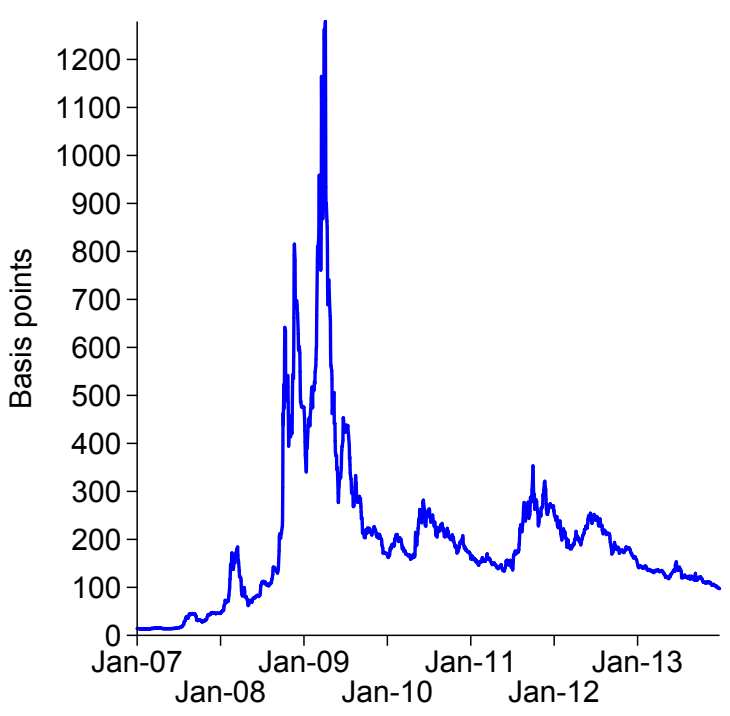

Notes: The left panel plots the value-weighted total return index for publicly traded insurers, banks, and the entire CRSP value-weighted index. The right panel plots the equity value-weighted annual premium to insure $\$ 10,000$ of debt for a period of 5 years for AFL, ALL, LNC, MET, PRU, and TMK.

\section{Macro Implications of Asset Insulator View}

In this section we document the macroeconomic importance of the asset insulator role of life insurers during the 2008-09 crisis. As a starting point, figure 7 illustrates the financial distress of the life insurance sector during the period. The left panel shows the stock return index for publicly traded life insurers plotted against commercial banks and the value-weighted CRSP index for comparison. The insurance sector has the largest peak-to-trough decline of the three sectors. The right panel shows the equity value-weighted average CDS spread for the six insurers with liquid CDS throughout the period. From a low of essentially zero before the crisis, the spread rises beginning in 2008 and peaks above 1200 basis points in March 2009 before declining to a "new normal" range in the latter part of that year. The distress evident in figure 7 explains why we treated the 2008-09 period as one of heightened liquidation risk in the previous section.

choices. The pass-through evidence here also helps to reconcile the evidence in Chodorow-Reich (2014) that life insurers' stock prices rose sharply during the crisis on dates when the Federal Reserve took actions to lower interest rates, a result at odds with the duration mismatch of insurers but consistent with the sharp rise in the value of portfolio holdings passing through into the equity at a high rate. 
Remarkably, franchise value actually increased by tens of billions of dollars during the crisis. Figure 8 shows this result by comparing the aggregate dollar change in insurers' assets net of liabilities during the crisis to the drop in equity. To construct the figure, we first calculate the capital gain/loss on the market (i.e. outside) value of publicly-traded insurers' securities holdings using the fair value reporting requirements imposed by NAIC and the procedure described in section 5.4 to compute security-level gains and losses. For 2008, the fair market value of securities declined by $\$ 30$ billion. Next, using the effective duration of each security together with the Treasury yield curve we calculate the change in the value of the assets due to interest rate changes alone by summing over securities the buy-and-hold return for a Treasury security of the same effective duration. ${ }^{26}$ For 2008, the decline in interest rates alone would have raised the market value of insurers' securities holdings by $\$ 96$ billion instead of the $\$ 30$ billion decline actually observed. Thus, the non-interest rate component of the market value of the assets declined by $\$ 126$ billion. If insurers' liabilities have duration equal to their security holdings (a conservative assumption), then the net change in the market value of assets less liabilities equals this $\$ 126$ billion decline, shown in the left blue bar in figure $8{ }^{27}$

In fact, the left red bar shows that insurers' equity dropped by "only" $\$ 80$ billion in 2008: franchise value increased. This result runs counter to Modigliani-Miller and is even more at odds with the financial distress view that a deteriorating financial situation destroys firm value. The dynamic reverses in 2009 as the market prices of assets recover by more than insurer equity.

The insulator theory explains why insurers were partly shielded from the large fluctuations in market prices of assets during the crisis. Figure 1 illustrate these dynamics formally. An increase in market illiquidity corresponds to a decline in the

\footnotetext{
${ }^{26}$ When the holding changes due to purchases, sales, dividends, or pre-payments, we adjust the matched Treasury holding accordingly.

${ }^{27}$ This calculation understates the decline in the market value of assets less liabilities for two reasons. First, we impute the change in liabilities using the duration of assets because we do not have data on the duration of liabilities directly. However, industry analysts generally agree that insurance company liabilities are longer duration than their assets, such that our calculation understates the increase in the value of liabilities due to the sharp drop in interest rates in 2008. Second, the calculation does not include balance sheet losses resulting from guaranteed income annuities, direct holdings of mortgages or real estate, or assets held outside of the insurance subsidiary. On the other hand, the figure does not include the changes in the value of public debt since we do not have CDS prices for most of our sample. However, this omission should not affect the result much. For example, in 2008 total equity at the 6 insurers for which we do have CDS prices declined by $\$ 75$ billion. Applying the CDS curve and Treasury yield curve to the maturity structure of public debt outstanding for these insurers, we estimate a decline in the value of debt of $\$ 2$ billion, the result of an increase in value of $\$ 6$ billion from the decrease in interest rates and a fall in value of $\$ 8$ billion from the higher default risk.
} 
Figure 8: Aggregate Changes in Assets, Liabilities, and Market Equity

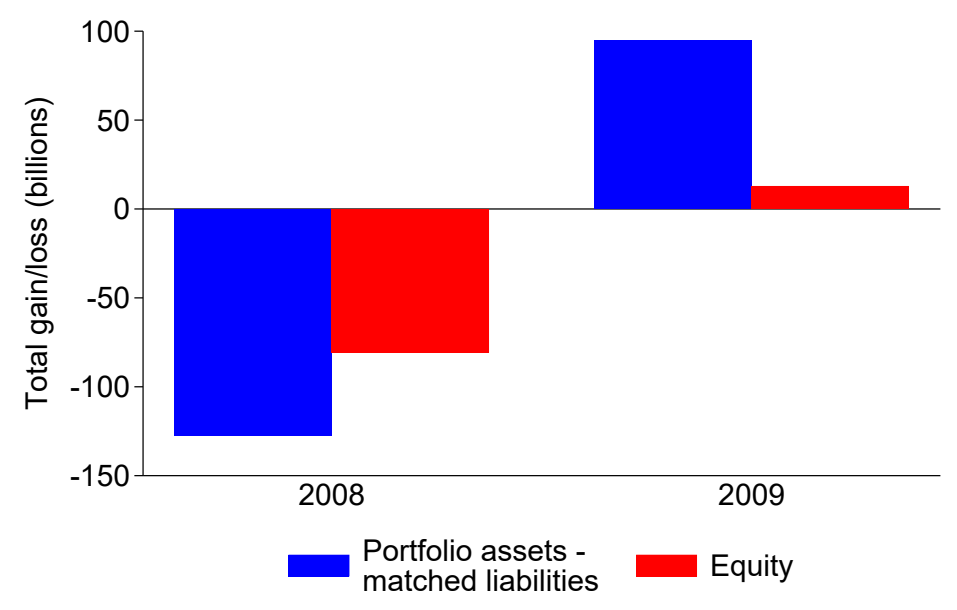

Notes: The blue bars show the fair value capital gain/loss on assets reported in NAIC schedule BA and $\mathrm{D}$ minus the gain/loss on a portfolio of Treasuries constructed by matching each cusip to a U.S. Treasury of the same duration. The red bars show the total change in market equity.

wedge $\omega$. This change lowers directly the value of the assets in the market and hence the Modigliani-Miller value of the firm. However, far from default, a change in $\omega$ has a small effect on firm equity. As a result, franchise value rises. In the figure, the two points $\mathrm{N}$ and $\mathrm{J}$ derive from the same value of $A^{\text {in }}$ but different values of $\omega$. The increase in vertical distance from the Modigliani-Miller line when moving from point $\mathrm{N}$ to point $\mathrm{J}$ reveals the increase in franchise value. Of course, life insurers also became financially distressed during the 2008-09 crisis. We represent this distress as a decline in $A^{\text {in }}$, or a movement from point $\mathrm{J}$ to point $\mathrm{C}$. As they approach default, insurers lose the ability to insulate assets from the market. Indeed, a large enough decrease in $A^{\text {in }}$ could reverse the increase in value creation coming from the lower $\omega$; in the extreme case of $A^{\text {in }} \rightarrow \underline{A}$, value creation from insulation ceases. Which of the two effects dominate is an empirical question. In the figure, as in the data, the overall change in franchise value when moving from $\mathrm{N}$ to $\mathrm{C}$ is positive.

These results highlight a core tension in both the theory and the data. Periods of financial turmoil and market dislocation represent prime opportunities for asset insulators. Yet, such periods may also coincide with insulators becoming financially distressed, jeopardizing their ability to insulate. Thus, asset insulation may be most fragile exactly when it is most valuable. The combination of high pass-through and high franchise value during the financial crisis demonstrates this tension for life in- 
surers. $^{28}$

\section{Conclusion}

We have proposed that financial intermediaries can act as asset insulators, institutions which hold assets for the long run to protect valuations from consequences of exposure to financial markets. The balance sheets of life insurers exemplify an asset insulation strategy. Insurers hold illiquid and risky assets for long intervals, in contrast to the classic duration-matching of liabilities view of their portfolio choice; they target purchases toward assets below their long-run value; and they have stable liabilities to back an insulation strategy.

The pass-through of the market value of assets into market equity is a useful metric to discriminate asset insulation from other theories. Using detailed security-level holdings data matched to the universe of corporate bond trades, we estimate that outside of the 2008-09 financial crisis an insurer's equity decreases by as little as 15 cents in response to a one dollar drop in the market value of its assets. During the crisis, the pass-through rises to approximately 1 . Our theory interprets the higher passthrough during the crisis as resulting from the deterioration in the financial health of insurers, which threatened their ability to act as long-lived investors. This rise in the pass-through occurred alongside an increase in the overall value of insulation in the crisis. Therefore, while insurers lost the ability to insulate at the margin, the insulation across their entire balance sheet prevented the destruction of nearly $\$ 50$ billion of market equity in the financial sector at a crucial moment.

Our results depict a set of institutions which create private value through their ability to hold risky, illiquid assets for long intervals. Ascertaining whether these institutions create social value requires answering additional questions. On the one hand, the asset insulation view suggests a stabilizing role for these institutions, rather than the amplifying role sometimes attributed to them. Proposals to tightly regulate asset holdings might impair this function. On the other, the correlation between market illiquidity and the health of the financial sector makes the asset insulation function most fragile exactly when it is most valuable. Finally, we do not consider the social benefits of having a large share of assets trade on financial markets, such

\footnotetext{
${ }^{28}$ These results may also bear on issues of systemic risk. Acharya, Philippon, and Richardson (2016) define a firm's systemic risk as its contribution to an aggregate capital shortfall in the financial sector. While the comovement of stock prices in figure 7 indicates a strong correlation of life insurer distress and the overall market, figure 8 suggests the capital shortfall would be even worse if the assets were not insulated inside the life insurance sector.
} 
as price discovery and liquidity. We leave these questions to future work. 


\section{References}

Acharya, V., T. Philippon, And M. Richardson (2016): The Economics, Regulation and Systemic Risk of Insurance Markets, Oxford University Press, chap. Measuring Systemic Risk For Insurance Companies.

Aminud, Y. AND H. Mendelson (1986): "Asset pricing and the bid-ask spread," Journal of financial Economics, 17, 223-249.

AN, X., Y. Deng, AND S. GABRIEl (2011): "Asymmetric information, adverse selection, and the pricing of CMBS," Journal of Financial Economics, 100, 304-325.

BAI, J. (2009): "Panel data models with interactive fixed effects," Econometrica, 77, $1229-1279$.

BARBERIS, N. AND R. THALER (2003): "A survey of behavioral finance," Handbook of the Economics of Finance, 18, 1051-1121.

BECKER, B. AND V. IVASHINA (2015): "Reaching for yield in the bond market," The Journal of Finance, 70, 1863-1902.

BERK, J. B. AND R. C. GReEN (2004): "Mutual fund flows and performance in rational markets," Journal of political economy, 112, 1269-1295.

BERK, J. B. AND R. STANTON (2007): "Managerial ability, compensation, and the closed-end fund discount," The Journal of Finance, 62, 529-556.

Bernanke, B. (1983): "Nonmonetary Effects of the Financial Crisis in the Propagation of the Great Depression," American Economic Review, 73, 257-276.

Bessembinder, H., W. F. Maxwell, and K. Venkataraman (2013): “Trading activity and transaction costs in structured credit products," Financial Analysts Journal, 69, 55-67.

Boyarchenko, N., A. Fuster, AND D. O. LuCCA (2015): "Understanding mortgage spreads," Tech. Rep. 674, FRB of New York Staff Report.

BREeden, D. T. (1994): "Complexities of hedging mortgages," The Journal of Fixed Income, 4, 6-41.

BRIYS, E. AND F. DE VARENNE (1997): "On the risk of insurance liabilities: debunking some common pitfalls," Journal of Risk and Insurance, 673-694. 
Brunnermeier, M. K. And Y. SAnnikov (2014): "A Macroeconomic Model with a Financial Sector," American Economic Review, 104, 379-421.

Calomiris, C. W. AND C. M. Kahn (1991): "The role of demandable debt in structuring optimal banking arrangements," The American Economic Review, 497-513.

Cherkes, M., J. SAgi, And R. Stanton (2009): "A liquidity-based theory of closedend funds," Review of Financial Studies, 22, 257-297.

Chodorow-Reich, G. (2014): "Effects of unconventional monetary policy on financial institutions," Brookings Papers on Economic Activity, Spring, 155-204.

De Long, J. B., A. Shleifer, L. H. Summers, ANd R. J. Waldmann (1990): “Noise trader risk in financial markets," Journal of Political Economy, 98, 703-738.

DeAngelo, H., L. DeAngelo, And S. C. Gilson (1994): "The collapse of first executive corporation junk bonds, adverse publicity, and the "run on the bank" phenomenon," Journal of Financial Economics, 36, 287-336.

(1996): "Perceptions and the politics of finance: junk bonds and the regulatory seizure of First Capital Life," Journal of Financial Economics, 41, 475-511.

Diamond, D. W. AND P. H. Dybvig (1983): "Bank runs, deposit insurance, and liquidity," Journal of Political Economy, 91, 401-419.

Duffie, D., N. Gârleanu, AND L. H. Pedersen (2005): "Over-the-counter markets," Econometrica, 73, 1815-1847.

Edwards, A. K., L. E. HARRis, AND M. S. Piwowar (2007): "Corporate bond market transaction costs and transparency," The Journal of Finance, 62, 1421-1451.

Ellul, A., C. Jotikasthira, AND C. T. Lundblad (2011): "Regulatory pressure and fire sales in the corporate bond market," Journal of Financial Economics, 101, $596-620$.

Ellul, A., C. Jotikasthira, C. T. Lundblad, AND Y. WANG (2015): "Is historical cost accounting a panacea? Market stress, incentive distortions, and gains trading," The Journal of Finance, 70, 2489-2538.

Foley-Fisher, N., B. Narajabad, and S. Verani (2016): "Self-fulfilling Runs: Evidence from the U.S. Life Insurance Industry," Tech. rep., Federal Reserve Board of Governors. 
Gabaix, X., A. Krishnamurthy, And O. Vigneron (2007): "Limits of arbitrage: Theory and evidence from the mortgage-backed securities market," The Journal of Finance, 62, 557-595.

GILCHRIST, S. AND E. ZAKRAJŠEK (2012): "Credit spreads and business cycle fluctuations," American Economic Review, 102, 1692-1720.

Gorton, G. AND G. Pennacchi (1990): "Financial intermediaries and liquidity creation," The Journal of Finance, 45, 49-71.

Gottlieb, D. AND K. Smetters (2014): “Lapse-based insurance," Tech. rep., University of Pennsylvania.

Green, R., B. Hollifield, AND N. SchÜRHOFF (2007): "Financial intermediation and the costs of trading in an opaque market," Review of Financial Studies, 20, $275-314$.

GreEnwood, J. AND S. G. HANSON (2013): "Issuer quality and corporate bonds," Review of Financial Studies, 26, 1483-1525.

Gromb, D. And D. Vayanos (2010): "Limits of arbitrage," Annual Review of Financial Economics, 2, 251-276.

Hanson, S. G., A. Shleifer, J. C. Stein, And R. W. Vishny (2015): "Banks as patient fixed-income investors," Journal of Financial Economics, 117, 449-469.

HARRIS, L. E. AND M. PIWOWAR (2006): "Secondary trading costs in the municipal bond market," The Journal of Finance, 61, 1361-1397.

He, Z. And A. Krishnamurthy (2013): "Intermediary Asset Pricing," American Economic Review, 103, 732-70.

Ho, C. AND N. MUISE (2011): "U.S. individual life insurance persistency," Tech. rep., LIMRA.

KacPerczyk, M., S. Van Nieuwerburgh, AND L. Veldkamp (2016): "A Rational Theory of Mutual Funds' Attention Allocation,” Econometrica, 84, 571-626.

Koijen, R. S., S. VAn Nieuwerburgh, AND M. Yogo (2016): "Health and Mortality Delta: Assessing the Welfare Cost of Household Insurance Choice," The Journal of Finance, 71, 957-1010. 
KoIJEn, R. S. AND M. Yogo (2015): "The cost of financial frictions for life insurers," American Economic Review, 105, 445-75.

- (2016): "Shadow insurance," Econometrica, 84, 1265-1287.

Lamont, O. AND R. Thaler (2003): "Can the Market Add and Subtract? Mispricing in Tech Stock Carve-outs," Journal of Political Economy, 111, 227-268.

Lee, C., A. Shleifer, AND R. H. Thaler (1991): "Investor sentiment and the closed-end fund puzzle," The Journal of Finance, 46, 75-109.

MALKIEL, B. G. (1977): "The valuation of closed-end investment-company shares," The Journal of Finance, 32, 847-859.

MCMillan, R. (2013): "Industry surveys: Insurance: Life \& health,”.

Merrill, C., T. D. Nadauld, R. M. Stulz, and S. M. Sherlund (2014): "Were there fire sales in the RMBS market?" Tech. rep., Federal Reserve Board of Governors.

Nissim, D. (2013): "Relative valuation of US insurance companies," Review of Accounting Studies, 18, 324-359.

NozAWA, Y. (2017): "What drives the cross-section of credit spreads?: A variance decomposition approach," Journal of Finance, 72, 2045-2072.

Paulson, A., R. J. Rosen, R. McMenamin, and Z. Mohey-Deen (2012): "How liquid are US life insurance liabilities?" Chicago Fed Letter, 302.

SHLEIfER, A. AND R. ViShny (1997): "The limits of arbitrage," Journal of Finance, $52,35-55$.

- (2011): "Fire sales in finance and macroeconomics," Journal of Economic Perspectives, 25, 29-48.

Van Nieuwerburgh, S. and L. Veldkamp (2010): "Information Acquisition and Under-Diversification," The Review of Economic Studies, 77, 779-805. 


\section{Asset Insulators \\ Online Appendix}

Gabriel Chodorow-Reich Andra Ghent Valentin Haddad

August 2018 


\section{A A Microfoundation for Insulators}

We present an equilibrium model which gives rise to three results. First, the limited ability of long-term investors to expend capital in a particular market gives rise to the coexistence of two marginal valuations for the asset: the market price and a long-run value. Second, shocks specific to trading in the asset market - noise trader risk in this setting - affect the market value of the asset but not its long-run value. Third, when long-run investors access the asset market through a publicly traded insulator, the price of the insulator coincides with the long-run value of the asset. To make these points, we build on De Long et al. (1990), adding long-run investors facing limits to arbitrage.

Setup. We consider an infinite horizon setting in which time, $t=0,1, \ldots$, is discrete. There are two assets: a risk-free and a risky asset. The risk-free asset pays coupon $r$ each period and can be freely created from or transformed back into a unit of consumption good, so its price is 1 always. The risky asset also pays coupon $r$ each period, but is in fixed supply $S$. We denote $p_{t}$ the price of the risky asset at date $t$.

Three types of agents populate the economy each period: a mass $M_{n}$ of noise traders, a mass $M_{s r}$ of sophisticated short-lived investors, and a mass $M_{l r}$ of long-run investors. Noise traders and sophisticated short-lived investors live for two periods: they are born and trade at date $t$, and consume at date $t+1$. Both types of agents have CARA utility with risk aversion $\gamma$. Noise traders misperceive the change in price between $t$ and $t+1$ by an amount $\rho_{t} \sim \mathcal{N}\left(0, \sigma_{\rho}^{2}\right)$. We assume $\rho_{0}=0$. All other investors have rational expectations, which we denote by the conditional expectation operator $\mathbb{E}_{t}$.

Long-run investors are born at date 0 and live forever. They are risk-neutral, and discount time at rate $r$. They face two limits to arbitrage. First, only a fraction $\alpha \in$ $[0,1]$ of long-run traders can access the asset market. Second, when they access the risky asset market, they can only deploy one unit of wealth in it. The first assumption captures the limited sophistication — both technological and informational — of many agents in the economy, in particular households, which renders them unable to access complex asset markets. The second assumption captures the limitation of access to leverage for many investors. To simplify derivations, we further assume, as is often the case in practice, that long-run investors are buy-and-hold. They invest at date 0 and hold their positions forever. 
Equilibrium. We conjecture that price changes are normally distributed, with conditional variance denoted by $\sigma_{p, t+1}^{2}$. The demand for the risky asset from short lived investors then follows the classic CARA formula:

$$
D_{t}^{s r}=\frac{r+\mathbb{E}_{t}\left[p_{t+1}\right]-(1+r) p_{t}}{\gamma \sigma_{p, t+1}^{2}}
$$

The demand is the ratio of the expected excess profits from investing in the risky asset rather than the risk-free asset and the product of risk aversion with the variance of price change. Demand from noise traders is similar, incorporating their biased expectations of price changes:

$$
D_{t}^{n}=\frac{r+\mathbb{E}_{t}\left[p_{t+1}\right]+\rho_{t}-(1+r) p_{t}}{\gamma \sigma_{p, t+1}^{2}}
$$

The portfolio choice problem of long-run traders admits a corner solution: they invest in the risky asset only if its lifetime returns dominate the risk-free asset. Because both assets offer the same cash-flows, this happens if and only if the current price of the risky asset is lower than the price of the riskless asset, $p_{t} \leq 1$. Let us conjecture we are in this case. Then denote $S^{*}=S-\alpha M_{l r} / p_{0}$ the residual quantity of risky asset available after investment by long-run investors. Market-clearing for the risky asset corresponds to

$$
S^{*}=M_{n} D_{t}^{n}+M_{s r} D_{t}^{s r}
$$

Plugging in the optimal demand by these two groups of investors, we can rewrite this condition as:

$$
(1+r) p_{t}=r+\mathbb{E}_{t}\left[p_{t+1}\right]+\frac{M_{n}}{M_{n}+M_{s r}} \rho_{t}-\gamma \frac{S^{*}}{M_{n}+M_{s r}} \sigma_{p, t+1}^{2} .
$$

If we additionally guess that the variance term is constant, we can plug in recursively to obtain:

$$
p_{t}=1+\frac{1}{1+r} \frac{M_{n}}{M_{n}+M_{s r}} \rho_{t}-\frac{1}{r} \gamma \frac{S^{*}}{M_{n}+M_{s r}} \sigma_{p, t+1}^{2} .
$$

We can now go back to our three conjectures. With the formula above, the variance of 
the price is constant, and plugging in gives:

$$
p_{t}=1+\frac{1}{1+r} \frac{M_{n}}{M_{n}+M_{s r}} \rho_{t}-\frac{1}{r(1+r)^{2}} \frac{S^{*}}{M_{n}+M_{s r}}\left(\frac{M_{n}}{M_{n}+M_{s r}}\right)^{2} \gamma \sigma_{\rho}^{2} .
$$

Further, the price is normally distributed and is less than 1 when $\rho_{t}=0$. All that remains is to solve for $S^{*}$. The residual quantity is the unique solution of:

$$
\frac{\alpha M_{l r}}{S-S^{*}}=1-\frac{1}{r(1+r)^{2}} \frac{S^{*}}{M_{n}+M_{s r}}\left(\frac{M_{n}}{M_{n}+M_{s r}}\right)^{2} \gamma \sigma_{\rho}^{2} .
$$

A solution exists as long as $\alpha M_{l r}$ is not too large. ${ }^{29}$

Comments. Two distinct valuations for the risky asset are prevalent in this economy. Long-run investors' marginal willingness to pay for a unit of the risky asset is 1 , its long-run value. But the asset trades on a market at a different price, $p_{t}$, the marginal willingness to pay of noise traders and short-run investors.

The mismatch between these values comes from shocks affecting the market value of the asset but not the long-run value: noise trader risk. On average, the price of the risky asset is less than 1 because short-lived investors require a risk premium to hold it until next period's biases are revealed - the counterpart to $\bar{\omega}<1$ in our main setting. And, as noise traders are more or less pessimistic, they push the market price down more or less strongly, contracting or expanding the wedge. This mean-reverting force in the difference between the two values echoes the process we assume for $\omega_{t}$ in our main setting. From the expression for the price $p_{t}$, we can see that many other forces could lead to fluctuations in the wedge between the two values: changes in the risk aversion of traders, in the limits to arbitrage, etc.

Finally, we can consider the case of a publicly traded insulator. Consider an infinitesimal institution holding one unit of the risky asset forever, and that long-run investors all have access to trading it. Long-run investors would value it at the longrun value and absorb its supply. ${ }^{30}$ The price of the insulator coincides with the longrun value of the asset.

\footnotetext{
${ }^{29}$ When $\alpha M_{l r}$ is large, limits to arbitrage are not binding. Long-run investors absorb all the risky asset supply, and its equilibrium price is 1 .

${ }^{30}$ Just like the model allows for partial participation in the risky asset by long-term investors, we could also consider the case of a non-infinitesimal insulator while keeping a non-zero wedge.
} 


\section{B Solving the Model}

\section{B.1 Value of equity}

The exogenous laws of motions are

$$
\begin{aligned}
\frac{d A_{t}^{\text {in }}}{A_{t}^{\text {in }}} & =(r-c) d t+\sigma_{A} d Z_{t}^{A}, \\
d \omega_{t} & =-\kappa_{\omega}\left(\omega_{t}-\bar{\omega}\right) d t+\sigma_{\omega} \sqrt{\omega_{t}} d Z_{t}^{\omega} .
\end{aligned}
$$

The liquidation stopping time $T$ is the hitting time of the threshold $A_{0}$.

The value of the equity is

$$
E_{t}=\mathbb{E}_{t}\left[\int_{t}^{T} e^{-r(\tau-t)}(c-k) A_{\tau}^{\text {in }} d \tau+e^{-r(T-t)} \omega_{T} \underline{A}-\int_{t}^{\infty} e^{-r(\tau-t)} \ell d \tau\right]
$$

We drop the "in" superscript for simplicity and reorganize the equation:

$$
\begin{aligned}
E_{t}= & \mathbb{E}_{t}\left[\int_{t}^{T} e^{-r(\tau-t)}(c-k) A_{\tau} d \tau+e^{-r(T-t)} \omega_{T} \underline{A}-\int_{t}^{\infty} e^{-r(\tau-t)} \ell d \tau\right] \\
= & \underbrace{\mathbb{E}_{t}\left[\int_{t}^{\infty} e^{-r(\tau-t)}(c-k) A_{\tau} d \tau\right]}_{\text {no-liquidation asset value }}+\underbrace{\mathbb{E}_{t}\left[e^{-r(T-t)} \omega_{T} \underline{A}-\int_{T}^{\infty} e^{-r(\tau-t)}(c-k) A_{\tau} d \tau\right]}_{\text {liquidation adjustment }} \\
& -\underbrace{\mathbb{E}_{t}\left[\int_{t}^{\infty} e^{-r(\tau-t)} \ell d \tau\right]}_{\text {liabilities }} .
\end{aligned}
$$

The present value of liabilities is

$$
\int_{t}^{\infty} e^{-r(\tau-t)} \ell d \tau=\frac{\ell}{r}
$$

Note that $\mathbb{E}_{t}\left[A_{\tau} \mid A_{t}\right]=A_{t} \exp (r-c)(\tau-t)$. Therefore,

$$
\begin{aligned}
\mathbb{E}_{t}\left[\int_{t}^{\infty} e^{-r(\tau-t)}(c-k) A_{\tau} d \tau\right] & =A_{t} \int_{t}^{\infty}(c-k) \exp (-c(\tau-t)) d \tau \\
& =A_{t} \frac{c-k}{c}
\end{aligned}
$$


and

$$
\begin{aligned}
\mathbb{E}_{T}\left[\int_{T}^{\infty} e^{-r(\tau-t)}(c-k) A_{\tau} d \tau\right] & =\mathbb{E}_{T}\left[\int_{T}^{\infty} e^{-r(\tau-t)}(c-k) e^{(r-c)(\tau-T)} A_{T} d \tau\right] \\
& =e^{-r(T-t)} \frac{c-k}{c} A_{T}
\end{aligned}
$$

We can also compute expectations of $\omega_{\tau}$ for various values of $\tau$. For this remember the conditional mean of a CIR process is

$$
\mathbb{E}_{t}\left[\omega_{\tau} \mid \omega_{t}\right]=\omega_{t} e^{-\kappa_{\omega}(\tau-t)}+\bar{\omega}\left(1-e^{-\kappa_{\omega}(\tau-t)}\right)
$$

Plugging these results in the liquidation adjustment, and using the fact that, by definition, $A_{T}=A_{0}$, we have

$\mathbb{E}_{t}\left[e^{-r(T-t)} \omega_{T} \underline{A}-\int_{T}^{\infty} e^{-r(\tau-t)}(c-k) A_{\tau} d \tau\right]=\underline{A} \mathbb{E}_{t}\left[e^{-r(T-t)}\left[\left(\omega_{t}-\bar{\omega}\right) e^{-\kappa_{\omega}(T-t)}+\bar{\omega}-\frac{c-k}{c}\right]\right]$

We are left with computing $\mathbb{E}_{t}\left[e^{-r(T-t)}\right]$ and $\mathbb{E}_{t}\left[e^{-\left(r+\kappa_{\omega}\right)(T-t)}\right]$. The following lemma gives a general expression for this type of expectations.

Lemma 1. For any $\alpha \geq 0$, we have

$$
\mathbb{E}_{t}\left[e^{-\alpha(T-t)}\right]=\left(\frac{A_{t}}{\underline{A}}\right)^{-f(\alpha)}
$$

with

$$
f(\alpha)=\frac{r-c-\frac{1}{2} \sigma_{A}^{2}+\sqrt{\left(r-c-\frac{1}{2} \sigma_{A}^{2}\right)^{2}+2 \sigma_{A}^{2} \alpha}}{\sigma_{A}^{2}} .
$$

The function $f$ is positive and increasing.

Proof. Define $M_{t}=e^{-\alpha t}\left[\frac{A_{t}}{\underline{A}}\right]^{-\tilde{\gamma}_{1}}$. Applying Ito's lemma gives

$$
d M_{t}=M_{t}\left[-\alpha-\tilde{\gamma}_{1}(r-c)+\frac{1}{2} \sigma_{A}^{2} \tilde{\gamma}_{1}\left(1+\tilde{\gamma}_{1}\right)\right] d t-\tilde{\gamma}_{1} \sigma_{A} M_{t} d Z_{t}^{A}
$$


Hence $M_{t}$ is a martingale if $\tilde{\gamma}_{1}$ solves

$$
\begin{aligned}
0 & =\left[\frac{1}{2} \sigma_{A}^{2}\right] \tilde{\gamma}_{1}^{2}+\left[-(r-c)+\frac{1}{2} \sigma_{A}^{2}\right] \tilde{\gamma}_{1}+[-\alpha] \\
\tilde{\gamma}_{1} & =\frac{(r-c)-\frac{1}{2} \sigma_{A}^{2} \pm \sqrt{\left((r-c)-\frac{1}{2} \sigma_{A}^{2}\right)^{2}+2 \sigma_{A}^{2} \alpha}}{\sigma_{A}^{2}} .
\end{aligned}
$$

Let us consider the positive root, calling it $\gamma_{1}$. In this case $M_{t}$ is uniformly bounded before the stopping time $T$. Doob's optional stopping theorem applies: $M_{t}=E_{t}\left[M_{T}\right]$. Hence, substituting the definition of $M_{t}$,

$$
\begin{aligned}
& e^{-\alpha t}\left[\frac{A_{t}}{\underline{A}}\right]^{-\gamma_{1}}=E_{t}\left[e^{-\alpha T}\right], \\
& E_{t}\left[e^{-\alpha(T-t)}\right]=\left[\frac{A_{t}}{\underline{A}}\right]^{-\gamma_{1}} .
\end{aligned}
$$

This last expression coincides with our lemma.

Using this lemma, we obtain the value of equity:

$$
E_{t}=A_{t} \frac{c-k}{c}+\underline{A}\left(\frac{A_{t}}{\underline{A}}\right)^{-f\left(r+\kappa_{\omega}\right)}\left(\omega_{t}-\bar{\omega}\right)+\underline{A}\left(\frac{A_{t}}{\underline{A}}\right)^{-f(r)}\left(\bar{\omega}-\frac{c-k}{c}\right)-\frac{\ell}{r} .
$$

\section{B.2 Pass-through}

We can compute the laws of motion for $E_{t}$ and $A_{t}^{\text {out }}$ using Ito's lemma. We drop the $d t$ terms as they do not enter the pass-through calculation, and ignore the "in" superscript. For the equity value, we obtain:

$$
\begin{aligned}
d E_{t}= & \left(\frac{c-k}{c}-\frac{f\left(r+\kappa_{\omega}\right)}{A_{t}}\left(\frac{A_{t}}{\underline{A}}\right)^{-f\left(r+\kappa_{\omega}\right)} \underline{A}\left(\omega_{t}-\bar{\omega}\right)-\frac{f(r)}{A_{t}}\left(\frac{A_{t}}{\underline{A}}\right)^{-f(r)} \underline{A}\left(\bar{\omega}-\frac{c-k}{c}\right)\right) d A_{t} \\
& +\underline{A}\left(\frac{A_{t}}{\underline{A}}\right)^{-f\left(r+\kappa_{\omega}\right)} d \omega_{t}
\end{aligned}
$$

For the outside value of the assets, we obtain:

$$
d A_{t}^{\text {out }}=\omega_{t} d A_{t}+A_{t} d \omega_{t}
$$


We can then compute the pass-through, remembering that $\operatorname{cov}\left(d A_{t}, d \omega_{t}\right)=0$ :

$$
\begin{aligned}
P T= & \frac{<d E_{t}, d A_{t}^{\text {out }}>}{\left(d A_{t}^{\text {out }}\right)^{2}} \\
= & \frac{\omega_{t}^{2} d A_{t}^{2}}{\omega_{t}^{2} d A_{t}^{2}+A_{t}^{2} d \omega_{t}^{2}}\left[\frac{\frac{c-k}{c}}{\omega_{t}}-\frac{f\left(r+\kappa_{\omega}\right)}{\omega_{t} A_{t}}\left(\frac{A_{t}}{\underline{A}}\right)^{-f\left(r+\kappa_{\omega}\right)} \underline{A}\left(\omega_{t}-\bar{\omega}\right)-\frac{f(r)}{\omega_{t} A_{t}}\left(\frac{A_{t}}{\underline{A}}\right)^{-f(r)} \underline{A}\left(\bar{\omega}-\frac{c-k}{c}\right)\right] \\
& +\frac{A_{t}^{2} d \omega_{t}^{2}}{\omega_{t}^{2} d A_{t}^{2}+A_{t}^{2} d \omega_{t}^{2}}\left[\left(\frac{A_{t}}{\underline{A}}\right)^{-f\left(r+\kappa_{\omega}\right)-1}\right] .
\end{aligned}
$$

We define the fractions of variance of $d A_{t}^{\text {out }}$ coming from the two shocks

$$
\begin{aligned}
V_{A} & =\frac{\omega_{t}^{2} d A_{t}^{2}}{\omega_{t}^{2} d A_{t}^{2}+A_{t}^{2} d \omega_{t}^{2}}, \\
V_{\omega} & =\frac{A_{t}^{2} d \omega_{t}^{2}}{\omega_{t}^{2} d A_{t}^{2}+A_{t}^{2} d \omega_{t}^{2}} .
\end{aligned}
$$

\section{B.3 Alternative specifications}

We illustrate the robustness of our pass-through predictions by studying franchise value for alternative specifications of the model. Figure B.1 reports the analogue of figure 1 for three cases. Panel (a) reproduces the closed form result in the main text with liquidation boundary based on the inside value of the asset. Panel (b) corresponds to the assumption of a liquidation boundary based on the outside value of the asset. Panel (c) is the case of a liquidation boundary based on the inside value of the asset, but with positively correlated shocks to $A^{\text {in }}$ and $\omega$. In these last two cases, the equity values are computed through Monte-Carlo simulations.

When the insulator is in good financial health and $\omega$ is high (point $\mathrm{N}$ ), the economics of the pass-through do not depend on how liquidation occurs or the correlation structure of the shocks. In this situation, the insulator is far from the liquidation boundary so its specific form and the joint dynamics of shocks do not matter. Rather, the equity value depends almost entirely on the inside value of the asset because the asset is very likely to be held for the long-run. A decrease in the inside value of the asset therefore passes through close to one-to-one to the value of the equity while a shock to the wedge does not affect the value of the equity.

Close to liquidation, two forces drive the pass-through. First, because the assets are likely to be liquidated soon, the equity value is more closely tied to the market value of the assets. This pushes the pass-through to both types of shocks closer to 1 . Second, moving closer to the boundary erodes any insulation value by lowering the 
Figure B.1: Pass-through in the Asset Insulator Framework: Alternative Specifications
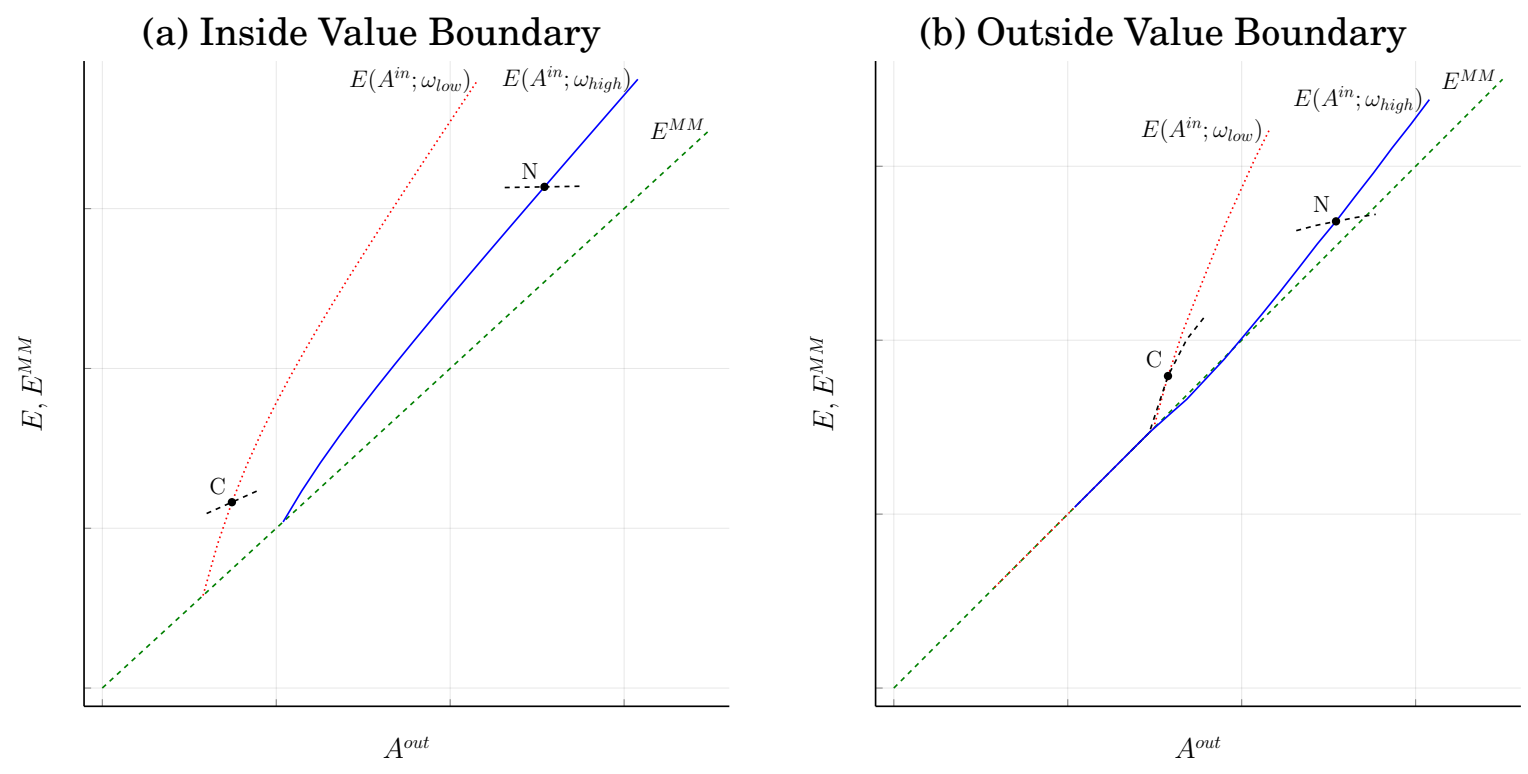

(c) Correlated $A^{\text {in }}$ and $\omega$

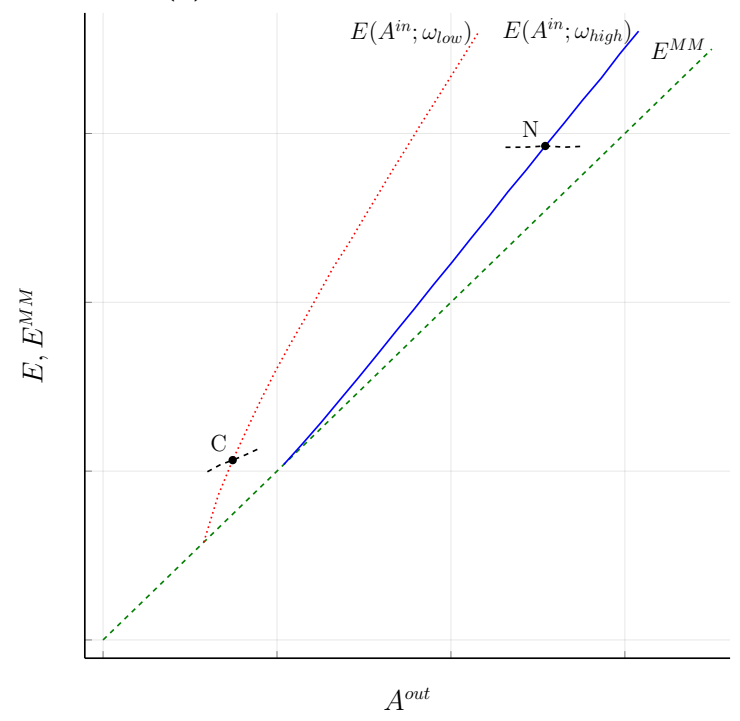

Notes: The figure illustrates the relationship between equity and asset value in the asset insulator framework. The dashed green line is the Modigliani-Miller benchmark and has a slope of 1 . The solid blue line plots equity as a function of the outside asset value for a fixed value $\omega_{\text {high }}$, while the dotted red line plots equity as a function of the outside asset value for a fixed value $\omega_{\text {low. }}$. The slopes of the blue and red lines give the conditional pass-through with respect to a change in the outside asset value coming from a change in $A^{\text {in }}$. The slopes of the dashed black lines give the conditional pass-through with respect to a change in the outside asset value coming from a change in $\omega$ at the two points $\mathrm{N}$ (for normal) and C (for crisis). 
expected holding horizon of the assets. This tends to push the pass-through further up, above 1 . When the liquidation boundary depends of the inside value of the asset, this second effect is only present for shocks to the inside value. At point $\mathrm{C}$ in panel (a) or (c), the dashed black line has a slope close to 1 , whereas the dotted red line has a slope larger than 1 . The only difference between these two cases is that the value from insulation is lower when the shocks are positively correlated. The lower value from insulation is because, with correlated shocks, low values of $A^{\text {in }}$ will force the firm to liquidate exactly when when it is least valuable to do, i.e., when $\omega$ is low. In contrast with these cases, when the liquidation boundary depends of the outside value of the asset, the second effect is present for both shocks. In panel (b), both the dashed black line and dotted red line exhibit a slope larger than 1 at point $\mathrm{C}$.

To summarize, in all these cases we obtain our main predictions. The pass-through should be lower than 1 outside of the crisis. During the crisis, the pass-through should rise, potentially to values larger than 1 .

\section{Balance Sheet Implications}

Insulators hold risky and illiquid assets. We want to show that the optimal portfolio takes a position in risky assets beyond the largest position at which liquidation occurs with probability 0 . Denote the risky asset as $j=1$ and the risk-free asset as $j=2$ and assume without loss of generality that $A_{1,0}^{\text {in }}=A_{2,0}^{\text {in }}=1$. Starting from a portfolio allocation with zero liquidation risk, consider an infinitesimal budgetneutral shift towards a risky portfolio, consisting of an increase in the risky asset position of $d s_{1}$ and a corresponding drop in the safe asset position of $d s_{2}=-\omega_{1,0} d s_{1}$.

This change has two effects on the value of equity: changing the present value of payoffs holding the liquidation stopping time constant, and changing the distribution of the liquidation stopping time. The first effect, because there is initially no liquidation, is proportional to the premium of the long-term value of the risky asset over its market value net of management costs: $\left([c-k] / c-\omega_{1,0}\right) d s_{1}$. This is a positive first-order term in $d s_{1}$.

The second effect is negative: default is more likely. Because of the assumption that default did not occur at all in the initial portfolio, it can occur at most in the states when the inside or outside value of the risky asset drops to value between 0 and $\omega_{1,0} d s_{1} / s_{1}$ at some future date $\tau$.

To bound the probability of such a drop occurring, first consider each part of the valuation separately. For the wedge $\omega_{1, t}$, remember that the Cox-Ingersoll-Ross pro- 
cess, under our parameter assumptions which guarantee $\omega_{1, t}$ is always strictly positive, has conditional distribution which is a non-central Chi-square with degrees of freedom equal to a value independent of $\tau$ and strictly larger than 2, which we note $\Theta$. Using a Taylor expansion of this distribution around 0 , we obtain immediately that the probability of liquidation is bounded uniformly by a term of order $d s_{1}^{\Theta / 2}$. Similarly, the inside value $A_{1, t}^{\text {in }}$ follows a geometric brownian motion, its probability of hitting zero is negligible against any power of $d s$, so in particular it is bounded by terms of order $d s^{\Theta / 2}$ as well. This immediately gives that the probability of hitting the inside value is bounded above by a term of this order. The outside value is the product of the two processes, its probability to fall in an infintesimal interval can be bounded using the following inequality which holds for any positive integer $n$ :

$$
\begin{aligned}
\mathbb{P}\left(\omega_{1, t} A_{1, t}^{\text {in }} \leq d s\right) \leq & \sum_{k=0}^{n-1} \mathbb{P}\left(\omega_{1, t} \leq d s^{\frac{1}{2}\left(1+\frac{k}{n}\right)}\right) \mathbb{P}\left(A_{1, t}^{\text {in }} \leq d s^{\frac{1}{2}\left(1-\frac{k+1}{n}\right)}\right) \\
& +\sum_{k=0}^{n-1} \mathbb{P}\left(\omega_{1, t} \leq d s^{\frac{1}{2}\left(1-\frac{k+1}{n}\right)}\right) \mathbb{P}\left(A_{1, t}^{\text {in }} \leq d s^{\frac{1}{2}\left(1+\frac{k}{n}\right)}\right) \\
\leq 2 n K d s^{\left(1-\frac{1}{n}\right) \frac{\Theta}{2}}, &
\end{aligned}
$$

where $K$ is the uniform bound on the individual probabilities. Because $n$ can be chosen freely, this is bounded by a term of order $(\Theta-\varepsilon) / 2$ for $\varepsilon$ arbitrarily small.

The value of insulation gains in these liquidation states is bounded above by the expected inside value of the asset at date $\tau$; when discounted at the risk-free rate and integrated across values of $\tau$ these gains are therefore bounded above by $1 / c$. Combining with the bound on the probability of liquidation, we find that the second effect is of order $d s_{1}^{(\Theta-\varepsilon) / 2}$.

The losses due to the prospect of liquidation are therefore negligible relative to the gains from insulating more assets.

Insulators have stable liabilities. We want to show that increasing the exogenous default intensity $\lambda$ lowers the equity of the insulator. Denote by $T$ the hitting time of the liquidation boundary, $T^{\prime}$ the hitting time of a Poisson process with intensity $\lambda$, and $T^{\vee}=\min \left(T, T^{\prime}\right)$. 
We can rewrite the value of the equity, where $f$ and $F$ denote the pdf and $\operatorname{cdf}$ of $T$ :

$$
\begin{aligned}
E_{t}+\ell / r & =\mathbb{E}_{t}\left[\begin{array}{ll}
\int_{t}^{T^{\vee}} e^{-r(\tau-t)}(c-k) A_{\tau}^{\text {in }} d \tau & +e^{-r\left(T^{\vee}-t\right)} \omega_{T^{\vee}} A_{T^{\vee}}^{i n}
\end{array}\right] \\
& =\mathbb{E}_{t}\left[\int_{t}^{\infty} e^{-r(\tau-t)}(c-k) A_{\tau}^{\text {in }} d \tau+e^{-r\left(T^{\vee}-t\right)}\left\{\omega_{T^{\vee}} A_{T^{\vee}}^{i n}-\int_{T^{\vee}}^{\infty} e^{-r\left(\tau-T^{\vee}\right.}(c-k) A_{\tau}^{\text {in }} d \tau\right\}\right] \\
& =\mathbb{E}_{t}\left[\int_{t}^{\infty} e^{-r(\tau-t)}(c-k) A_{\tau}^{\text {in }} d \tau+e^{-r\left(T^{\vee}-t\right)}\left\{\omega_{T^{\vee}}-\frac{c-k}{c}\right\} A_{T^{\vee}}^{i n}\right]
\end{aligned}
$$

Increasing $\lambda$ is adding early termination dates unconditionally to the realization of price dynamics. This lowers the value of the equity as long as early unconditional termination is always inefficient at any given date. This condition holds as long as insulation is valuable at date 0 and when $\omega_{t}=\bar{\omega}$, which occurs if $\bar{\omega}<(c-k) / c$.

\section{Additional Asset Allocation Details}

In this appendix, we provide additional evidence to confirm that insurers actively choose to hold risky assets rather than must do so to match the duration of their liabilities.

First, the small concentration of insurers' assets in U.S. Treasuries does not reflect constrained supply. To rule out this possibility, we match the insurer-cusip holdings of all Treasury securities in the SNL data (including of non-publicly traded insurers) with the total amount outstanding of each cusip reported in the Treasury Monthly Statement of the Public Debt and the fraction held by the Federal Reserve reported in the weekly statement of the System Open Market Account Holdings. ${ }^{31}$ Figure D.1 shows the resulting share of Treasuries outstanding (excluding Federal Reserve holdings) held by life insurers, by maturity and calendar year.

We use the Hanson et al. (2015, Appendix Table AII) liquidity weights summarized in table D. 1 below to assign liquidity weights at the year-insurer-asset class level. ${ }^{32}$ Table D.2 shows the illiquidity of our insurers by year. Despite our use of much

\footnotetext{
${ }^{31}$ The data on total Treasuries outstanding and SOMA holdings come from https://www. treasurydirect.gov/govt/reports/pd/mspd/mspd.htm and http://nyapps.newyorkfed. org/markets/soma/sysopen_accholdings.html, respectively.

${ }^{32}$ Hanson et al. (2015) assign an illiquidity weight of $50 \%$ to corporate bonds under the assumption that the corporate bonds are rated A- or higher. We maintain this weighting scheme despite most corporate bonds held by insurers having a rating below AA (see Table 3). Because lower rated corporate bonds are generally less liquid (see, for example, Edwards et al. (2007)), this assumption likely biases our measure of the illiquidity of insurers' holdings downwards.
} 
Figure D.1: Insurers' Share of U.S. Treasury Securities

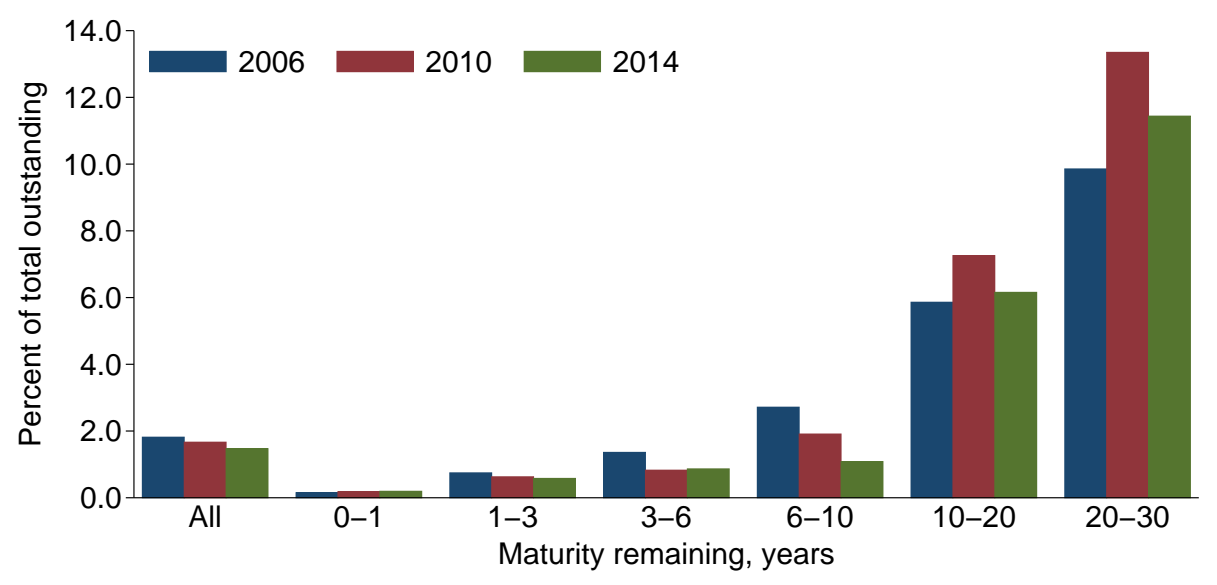

Notes: Each bar shows the percent of outstanding Treasuries with the maturity remaining indicated held by the life insurance sector. The definition of Treasuries outstanding used here excludes holdings of the Federal Reserve system.

more disaggregated data than Hanson et al., we obtain a very similar estimate of the illiquidity of our insurers of $60 \%$. By comparison, Hanson et al. find that banks' assets have an illiquidity measure of slightly above $60 \%$. 
Table D.1: Illiquidity Weights by Asset Class

\begin{tabular}{lc}
\hline \hline Asset Class & Illiquidity Weight (\%) \\
\hline ABS & 100 \\
Agency-MBS & 15 \\
Agency-Bond & 15 \\
Cash & 0 \\
CMBS & 100 \\
Common Stock & 50 \\
Corporate-financial & 50 \\
Corporate-other & 50 \\
Foreign sovereign & 50 \\
Foreign-other & 50 \\
Mortgages & 100 \\
Muni & 50 \\
Other & 100 \\
PLRMBS & 100 \\
Preferred Stock & 50 \\
Private Placement & 100 \\
Real Estate & 100 \\
TIPS & 0 \\
Treasuries & 0 \\
Treasuries-other & 0 \\
\hline \hline
\end{tabular}

Notes: Weights based on Hanson et al. (2015). We assume a weight of $100 \%$ for mortgages because the overwhelming majority of insurers' mortgages are commercial rather than residential mortgages.

Table D.2: Illiquidity of Insurers' Total Portfolios by Year

\begin{tabular}{lc}
\hline \hline Year & Illiquidity Measure \\
\hline 2005 & 58.3 \\
2006 & 60.4 \\
2007 & 61.2 \\
2008 & 59.2 \\
2009 & 60.0 \\
2010 & 60.7 \\
2011 & 60.5 \\
2012 & 59.8 \\
2013 & 60.1 \\
2014 & 59.3 \\
\hline Average & 60.0 \\
\hline \hline
\end{tabular}

Notes: See Table D.1 for weights assigned to individual asset classes. Summary is value-weighted by individual insurers' assets. $0=$ Completely liquid, 100=Completely illiquid. 


\section{E Additional Data Information}

We assess the accuracy of insurers' self-reported valuations of their assets in two ways. First, we collect prices for as many assets as possible from external sources such as TRACE, CRSP, and Bloomberg terminals. We are able to obtain external prices for approximately $38 \%$ of insurers' securities by value in any given year. The primary difficulty in obtaining external prices is that many of the assets they hold are highly illiquid. ${ }^{33}$ Table E.1 summarizes the difference in prices from what the insurers themselves report and third-party prices. In general, there is very little variation in asset prices reported in NAICs and external quotes. When we include outliers, insurers appear to slightly underreport the values of some securities as the mean raw price difference is $-1.2 \%$. However, after excluding outliers, the mean raw price difference is $0.2 \%$. The absolute price differences with and without outliers are $3.6 \%$ and $1.8 \%$. We thus feel confident using that insurers are reporting their asset values without significant bias to NAICs.

Table E.1: Differences Between Insurer-Reported and Third-Party Log Prices

\begin{tabular}{lcc}
\hline \hline & All Cusips & Excluding Outliers \\
\hline $\mathrm{N}$ & 328,230 & 326,684 \\
Mean Absolute & 0.036 & 0.018 \\
Median Absolute & 0.006 & 0.006 \\
Mean Raw & -0.012 & 0.002 \\
Median Raw & 0.000 & 0.000 \\
Mean Squared & 0.082 & 0.002 \\
Standard Deviation & 0.286 & 0.050 \\
P75 Absolute & 0.018 & 0.017 \\
P90 Absolute & 0.043 & 0.042 \\
P95 Absolute & 0.073 & 0.070 \\
P99 Absolute & 0.283 & 0.187 \\
Maximum Absolute & 13.816 & 0.999 \\
\hline \hline
\end{tabular}

Notes: All values as of Q4. Count (N) refers to number of CUSIPS for which external prices are available. Fair value per unit used for insurer-reported price. Raw difference calculated as log of insurer-reported less third-party value. Outliers are CUSIPS for which the insurer-reported value deviates by more than $100 \%$ from that reported by third-parties.

The second way we assess the accuracy of insurers' self-reported valuations is by comparing the prices reported by multiple insurers in our sample that hold the

\footnotetext{
${ }^{33}$ Edwards et al. (2007) report that about half of corporate bonds trade very infrequently. Bessembinder et al. (2013) find that only $20 \%$ of structured finance securities trade at all in a 20 -month period.
} 
same asset. Approximately 55\% of insurers' securities by value are held in securities that multiple insurers hold. Table E.2 details the deviations in prices reported across insurers. The mean and median standard deviations are $4.3 \%$ and $0.0 \%$. After excluding outliers, these statistics fall to just $0.9 \%$ and $0.0 \%$.

Table E.2: Cross-Insurer Standard Deviations for Insurer-Reported Log Prices by CUSIP

\begin{tabular}{lcc}
\hline \hline & All CUSIPS & Excluding Outliers \\
\hline $\mathrm{N}$ & 287,903 & 285,774 \\
Mean & 0.043 & 0.009 \\
Median & 0.000 & 0.000 \\
Standard Deviation & 0.277 & 0.036 \\
$\mathrm{P} 75$ & 0.004 & 0.004 \\
$\mathrm{P} 90$ & 0.017 & 0.016 \\
$\mathrm{P} 95$ & 0.043 & 0.035 \\
P99 & 1.687 & 0.190 \\
Maximum & 11.209 & 1.354 \\
\hline \hline
\end{tabular}

Notes: Q4 fair values used to calculate standard deviations. Count (N) refers to number of CUSIPS held by multiple insurers. Outliers are CUSIPS for which the differences in prices across insurers exceed $100 \%$.

We next provide further detail on holdings by insurer and asset illiquidity. Figure E.1 reports the asset class allocation for each insurer for the years 2005, 2009, and 2013. 


\section{Figure E.1: Portfolio Allocation by Insurer}

Panel A: 2005

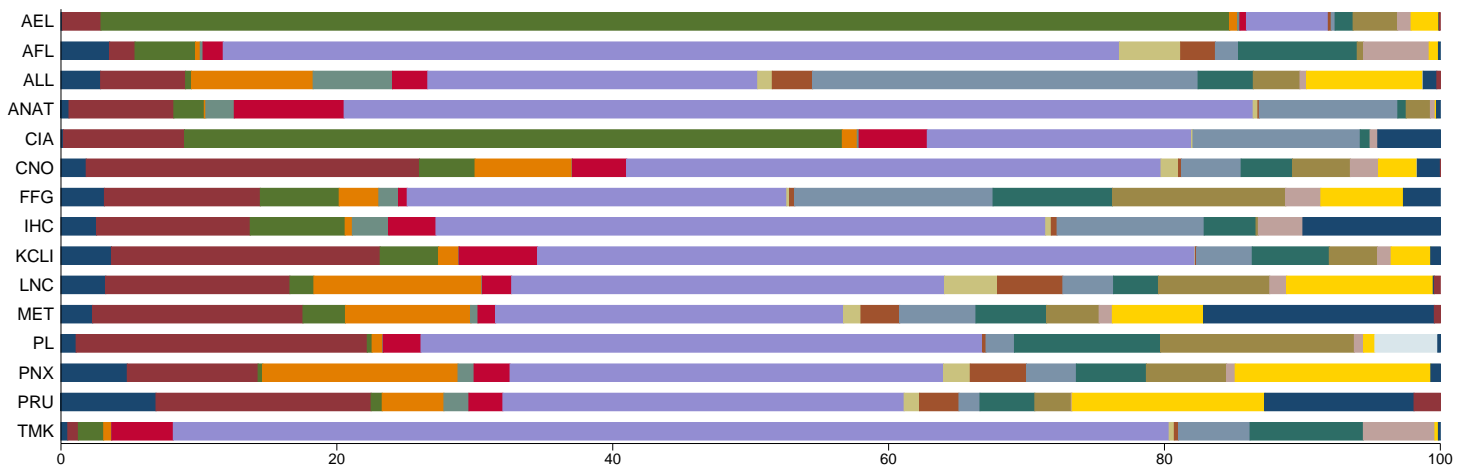

Panel B: 2009

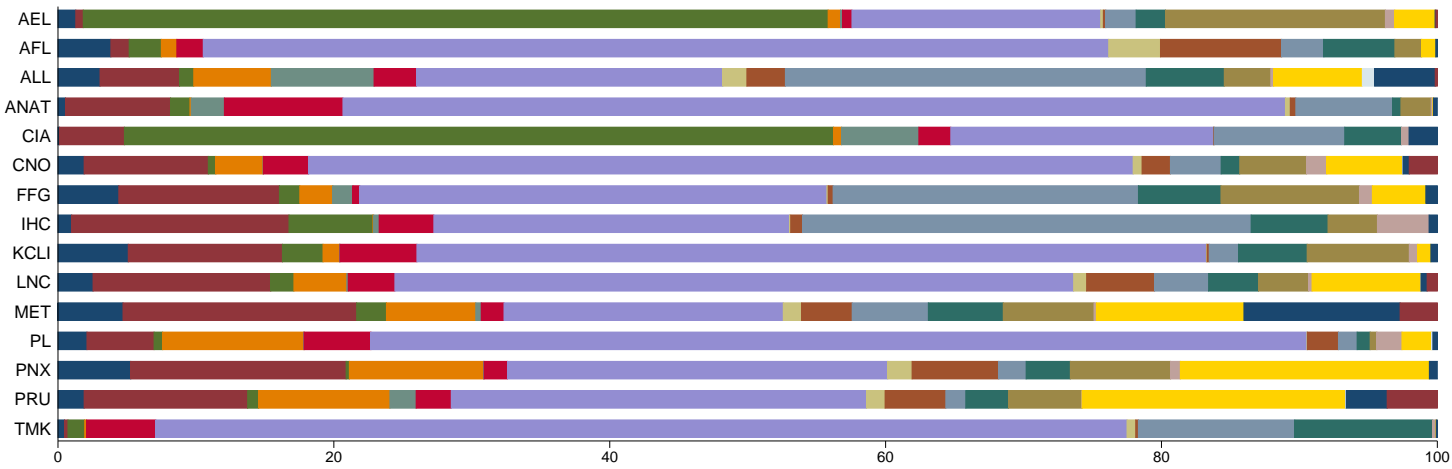

Panel C: 2013

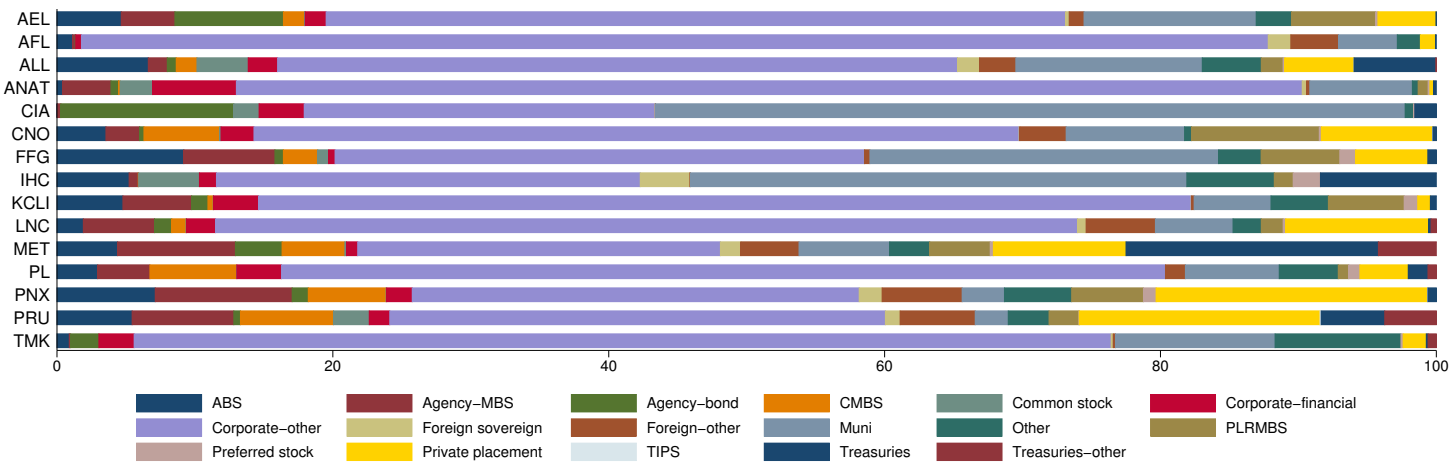

